DIW BERLIN

Discussion

Papers

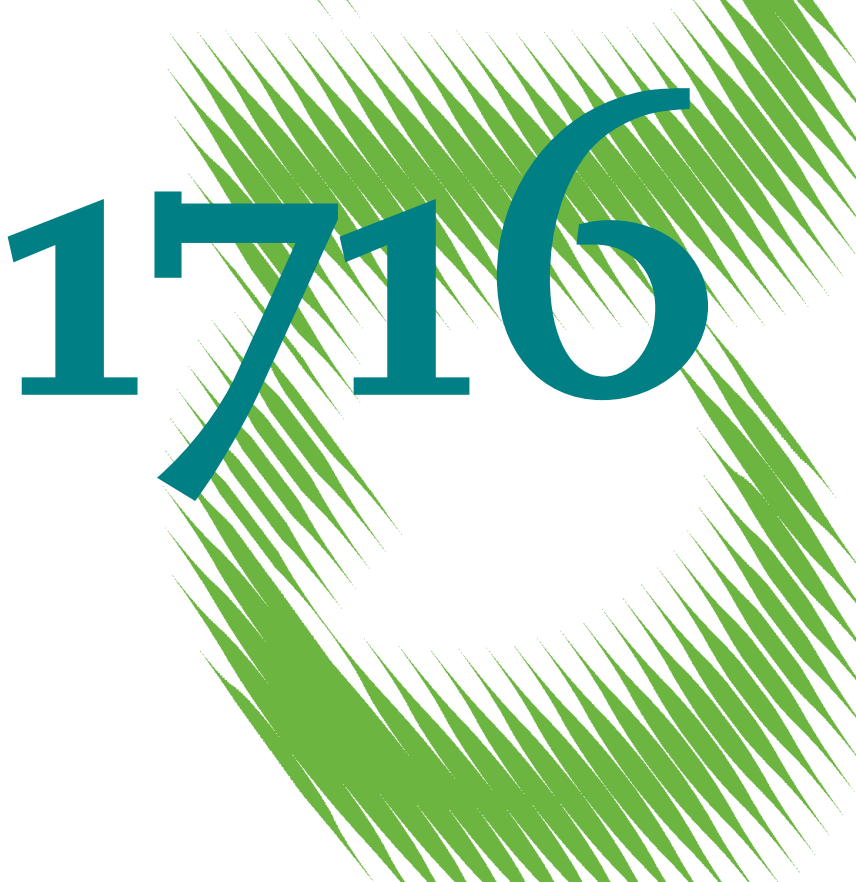

Insurance, Redistribution, and the Inequality of Lifetime Income 
Opinions expressed in this paper are those of the author(s) and do not necessarily reflect views of the institute.

IMPRESSUM

(C) DIW Berlin, 2017

DIW Berlin

German Institute for Economic Research

Mohrenstr. 58

10117 Berlin

Tel. +49 (30) $89789-0$

Fax +49 (30) $89789-200$

http://www.diw.de

ISSN electronic edition 1619-4535

Papers can be downloaded free of charge from the DIW Berlin website:

http://www.diw.de/discussionpapers

Discussion Papers of DIW Berlin are indexed in RePEc and SSRN:

http://ideas.repec.org/s/diw/diwwpp.html

http://www.ssrn.com/link/DIW-Berlin-German-Inst-Econ-Res.html 


\title{
Insurance, Redistribution, and the Inequality of Lifetime Income
}

\author{
Peter Haan* \\ Daniel Kemptner ${ }^{\dagger}$ \\ Victoria Prowse ${ }^{\ddagger}$
}

December 26, 2017

\begin{abstract}
In this paper, we study how the tax-and-transfer system reduces the inequality of lifetime income by redistributing lifetime earnings between individuals with different skill endowments and by providing individuals with insurance against lifetime earnings risk. Based on a dynamic life-cycle model, we find that redistribution through the tax-andtransfer system offsets around half of the inequality in lifetime earnings that is due to differences in skill endowments. At the same time, taxes and transfers mitigate around $60 \%$ of the inequality in lifetime earnings that is attributable to employment and health risk. Progressive taxation of annual earnings provides little insurance against lifetime earnings risk. The lifetime insurance effects of taxation may be improved by moving to a progressive tax on lifetime earnings. Similarly, the lifetime insurance and redistributive effects of social assistance may be improved by requiring wealthy individuals to repay any social assistance received when younger.
\end{abstract}

Key words: Lifetime earnings; lifetime income; tax-and-transfer system; taxation; unemployment insurance; disability benefits; social assistance; inequality; redistribution; insurance; endowments; risk; dynamic life-cycle models.

JEL classification: D63; H23; I24; I38; J22; J31.

${ }^{*}$ FU Berlin and DIW Berlin, phaan@diw.de

${ }^{\dagger}$ DIW Berlin, dkemptner@diw.de

${ }^{\ddagger}$ Department of Economics, Purdue University, vprowse@purdue.edu 


\section{Introduction}

The inequality of lifetime earnings is a key barometer of disparities in living standards. Indeed, to the degree that individuals can save and borrow, the inequality of lifetime earnings more accurately captures fundamental economic disparities than the inequality of annual earnings. Motivated by this observation, a growing literature has started to document the inequality of lifetime earnings. Despite earnings mobility over the life cycle, the inequality of lifetime earnings is substantial: Bönke et al. (2015) find that the distribution of the lifetime earnings of German men has a Gini coefficient around 0.2, and Guvenen et al. (2017) find that the 75th percentile of the lifetime earnings of American workers is around three times higher than the 25th percentile. Based on decompositions of the inequality of lifetime earnings, several studies have shown that the inequality in lifetime earnings is due to a combination of differences in skill endowments that are allotted early in life and chance differences in the shocks that individuals experience during their lifetimes.

In this paper, we study how well the tax-and-transfer system mitigates the inequalities in lifetime earnings that are due to endowments and we show how the tax-and-transfer system moderates the disparities in lifetime earnings that are due to shocks. We call the former effect the redistributive effect of the tax-and-transfer system and we call the latter effect the insurance effect of the tax-and-transfer system. While previous studies have shown that the inequality of lifetime after-tax-and-transfer earnings (i.e., lifetime income) is less than the inequality of lifetime earnings, we are the first to separately study how the tax-and-transfer system redistributes lifetime earnings and how it insures lifetime earnings risk.

There are three reasons why it is important to separate the insurance and redistributive effects of the tax-and-transfer system on lifetime income. First, information about the redistributive effect of the tax-and-transfer system speaks to how well taxes and transfers mitigate increases in the inequality of lifetime earnings that are driven by economic shifts that increase the returns to endowments. Relevant shifts include technological change that favors high ability workers and changes in the pattern of international trade that drive up the wage premium for a college degree. Second, studying how well taxes and transfers insure lifetime earnings risk highlights additional benefits from taxation, social assistance (or 'welfare') programs, and social insurance programs, such as unemployment insurance and disability benefits, compared to benefit calculations that focus on the effects of these programs on annual income or other short-term income measures. Third, by documenting the insurance and redistributive effects of the tax-and-transfer system, we are able to identify directions for policy reforms of taxes and social assistance that may improve the lifetime insurance and redistributive effects of the tax-and-transfer system.

We base our analysis on a dynamic life-cycle model of labor supply and consumption behavior. The model generates individual-level trajectories for earnings and after-tax-and-transfer income over the life cycle. The model thus provides the information that is needed to calculate 
lifetime earnings and lifetime income on an individual-by-individual basis. The model includes two key drivers of disparities in lifetime earnings: differences in skill endowments, specifically education and productive ability, and differences in the employment and health shocks that individuals encounter over the life cycle. Since the model also includes taxes and transfers, we can use the model to explore how the tax-and-transfer system insures against shocks that generate disparities in lifetime earnings and how taxes and transfers mitigate the inequality in lifetime earnings that arises from skill endowments. Furthermore, because we derive lifetime earnings and lifetime incomes from a grounded economic model in which optimal behavior depends on the nature of employment and health risk, we can study how the tax-and-transfer system insures against increases in risk while recognizing that individuals may adjust their behavior in response to risk increases, thereby limiting the insurance effect of taxes and transfers.

Our empirical analysis focuses on Germany. In line with most developed countries, the German tax-and-transfer system features progressive taxes, disability benefits for people who are experiencing bad health, unemployment insurance that provides temporary income replacement following a job loss, and social assistance that provide long-term support to low-income wealth-poor individuals. We embed a tax-and-transfer system based on the German system into our life-cycle model. We then estimate the parameters of the model using a Maximum Likelihood procedure that targets the patterns of labor supply and earnings that we observe in a sample of men taken from the German Socio-Economic Panel. We demonstrate that the estimated model has good in-sample fit. We also perform a validation exercise in which we show that the estimated model implies levels of inequality in lifetime earnings that match those observed in a comparable administrative dataset that was not used for estimation.

We find that the tax-and-transfer system is strongly progressive on a lifetime basis, despite taxes and transfers being based on annual earnings. Both insurance and redistribution contribute to the progressive effect of the tax-and-transfer system on lifetime income. Our results on redistribution suggest that the tax-and-transfer system will absorb around half of any additional inequality in lifetime earnings that is generated by skill-biased technological change or other economic shifts that increase the returns to skill endowments. Our analysis also suggests that the tax-and-transfer system will mitigate around $60 \%$ of the extra inequality in lifetime earnings generated by an increase in job separation risk, job offer risk, or health risk. The tax-and-transfer system, therefore, offers substantial insurance against lifetime earnings risk.

To understand the mechanisms behind the insurance and redistributive effects of the taxand-transfer system, we disaggregate the overall insurance and redistributive effects into components due to taxes, unemployment insurance, disability benefits, and social assistance. We find that: i) taxes are much more effective at redistributing lifetime income than insuring lifetime earnings risk; ii) although both unemployment insurance and disability benefits provide insurance, unemployment insurance redistributes lifetime earnings whereas disability benefits are not redistributive; and iii) social assistance is the most important transfer program for both insurance and redistribution. 
In more detail, taxes are highly redistributive on a lifetime basis due to a combination of the strongly progressive annual tax schedule and the empirical fact that individuals with endowments that are associated with high expected lifetime earnings also have high annual earnings. We trace the small insurance effect of taxes to the low returns to experience: among individuals with the same skill endowments, the annual tax rate increases only slightly with lifetime earnings because wages are relatively flat over the life cycle. The redistributive effect of unemployment insurance stems from the higher incidence of job separations among the low educated. Meanwhile, the absence of a redistributive effect for disability benefits reflects that, although eligibility for disability benefits is negatively related to expected lifetime earnings, the rate of benefit take-up among eligible individuals increases with expected lifetime earnings.

The large insurance and redistributive effects of social assistance reflect that social assistance is targeted at individuals with low annual income from other sources. Across all individuals, low annual income predicts low expected lifetime earnings, which makes social assistance redistributive. Similarly, among individuals who share the same skill endowments, low annual income predicts low lifetime earnings, thus explaining the insurance effect of social assistance. Interestingly, the wealth test for social assistance, which restricts benefits to individuals with limited assets, reduces the insurance and redistributive effects of social assistance. This reflects that the wealth test bites most often on individuals with low-to-intermediate lifetime earnings. These individuals often have low incomes in the middle and end of the life cycle, when they have accumulated sufficient wealth to make themselves ineligible for social assistance. In contrast, our results show that individuals with high lifetime earnings are more likely to have low income when they are young and, therefore, wealth poor.

When we consider the insurance effects of taxes and transfers in more detail, we find that the tax-and-transfer system offers essentially equal amounts of insurance against lifetime earnings risk stemming from job separation risk, job offer risk, and health risk. Irrespective of the source of risk, the insurance effect of the tax-and-transfer system mainly operates via transfers rather than taxes. However, the relative importance of unemployment insurance, disability benefits, and social assistance in providing insurance against lifetime earnings risk depends on the risk source. In particular, unemployment insurance offers better insurance against earnings risk due to an increase in job separation risk than against earnings risk due to a decrease in the job offer rate. Disability benefits, meanwhile, offer better insurance against earnings risk that is due to an increase in the risk of bad health than against earnings risk due to job separation or job offer risk. Social assistance is particularly effective at providing insurance against earnings risk that arises from a decrease in the job offer rate. This reflects that, because it is a permanent transfer, social assistance is effective at mitigating the lifetime earnings consequences of the increase in the duration of nonemployment spells that arises from a decrease in the job offer rate.

Our analysis suggests two directions for policy reforms that may improve the lifetime insurance and redistributive effects of the tax-and-transfer system. First, the small insurance effect 
of progressive annual taxes that we find highlights a drawback of annual taxation relative to multi-year or lifetime taxation. A progressive tax on lifetime earnings would directly target differences in lifetime earnings between individuals with the same skill endowments and, therefore, would be more effective at insuring lifetime earnings risk. Second, our finding that the wealth test for social assistance reduces the lifetime insurance and redistributive effects of the tax-and-transfer system suggests that the lifetime effects of social assistance might be improved without increasing costs by switching to a lifetime wealth test that requires individuals with high wealth later in life to repay any social assistance received when younger.

Our interest in the inequality of lifetime income is based on studies that document substantial inequities in lifetime earnings using administrative datasets (Björklund, 1993, Kopczuk et al., 2010, Aaberge and Mogstad, 2015, Bönke et al., 2015, Guvenen et al., 2017), statistical models (Bonhomme and Robin, 2009), or behavioral economic models (Keane and Wolpin, 1997, Flinn, 2002, Bowlus and Robin, 2004, Bowlus and Robin, 2012, Brewer et al., 2012). Our focus on the insurance and redistributive effects of the tax-and-transfer system is motivated by a related literature that shows that both risk and skill endowments contribute to the inequality of lifetime earnings (Keane and Wolpin, 1997, Flinn, 2002, Bowlus and Robin, 2004, Storesletten et al., 2004, Huggett et al., 2011). The importance of risk in explaining disparities in lifetime earnings is consistent with studies that show that individuals are subject to persistent earnings, health, and employment shocks (e.g., Meghir and Pistaferri, 2011). The role of skill endowments in driving lifetime earnings aligns with studies that show that education and non-cognitive skills are important determinants of lifetime earnings (e.g., Bhuller et al., 2017, Nybom, 2017).

Several papers have looked at the reallocative effect of taxes and transfers on a lifetime basis (Falkingham and Harding, 1996, Nelissen, 1998, Björklund and Palme, 2002, Pettersson and Pettersson, 2007, Ter Rele et al., 2007, Bovenberg et al., 2008, Bartels, 2012, Levell et al., 2017). This literature systematically finds that the reallocation of lifetime earnings through the tax-and-transfer system partially offsets disparities in lifetime earnings. Levell et al. (2017), for example, find that the inequality of lifetime income in the UK is about $25 \%$ lower than the inequality of lifetime earnings. Consistent with these findings, Blundell et al. (2015) show that taxes and transfers moderate the impacts of transitory and permanent earnings shocks. However, in contrast to our analysis, the previous literature has not separately considered how the tax-and-transfer system targets inequalities in lifetime earnings that are due to risk and how taxes and transfers mitigate the inequality in lifetime earnings that is attributable to skill endowments.

Our dynamic model of labor supply and consumption is in the spirit of the models introduced by Eckstein and Wolpin (1989), Keane and Wolpin (1997), and Imai and Keane (2004). Since we require information about lifetime income, as well as lifetime earnings, we follow, e.g., Low et al. (2010), Hoynes and Luttmer (2011), Shaw (2014), Low and Pistaferri (2015), Haan and Prowse (2015), and Blundell et al. (2016) by embedding a tax-and-transfer system into 
the life-cycle model. While this literature has considered individuals' willingness to pay for social insurance programs or other elements of the tax-and-transfer system, we focus on the implications of taxes and transfers for the inequality of lifetime income. In doing so, we make a connection to a literature that links inequality to economic growth and to socio-economic outcomes such as crime and conflict (see, e.g., Kelly, 2000, Panizza, 2002, Cramer, 2003).

This paper proceeds as follows. In Section 2 we define lifetime earnings and lifetime income. In Section 3 we describe the dynamic model that we use to derive lifetime earnings and lifetime income. In Section 4 we discuss the parameter estimates and demonstrate that the model has good in-sample and out-of-sample fit. In Section 5 we explore the insurance and redistributive effects of the tax-and-transfer system. In Section 6 we analyze how the tax-and-transfer system insures job separation risk, job offer risk, and health risk. In Section 7 we conclude by discussing some implications of our results.

\section{Earnings and income concepts}

We start with our definitions of earnings and income. An individual's annual earnings is composed of annual labor earnings and annual interest income. Using $i$ to index individuals and $t$ to denote age (measured in years), we have:

$$
\text { Earnings }_{i, t}=\text { LaborEarnings }_{i, t}+\text { InterestIncome }_{i, t} .
$$

We define the individual's annual income at age $t$ to be equal to his annual earnings, defined above, minus annual taxes plus the annual value of any government transfers:

$$
\text { Income }_{i, t}=\text { Earnings }_{i, t}-\text { Taxes }_{i, t}+\text { Transfers }_{i, t} .
$$

In other words, we use the term income to refer to after-tax-and-transfer earnings. Summing the individual's annual earnings over the life cycle yields the individual's lifetime earnings. Likewise, the individual's lifetime income is obtained by summing the individual's annual income over the life cycle.

While the exact nature of tax and transfer programs varies from one country to another, there are some broad similarities in how countries organize these programs. In particular, in most developed countries, taxes are progressive, and transfer programs include provisions for people experiencing bad health or disabilities, unemployment insurance that provides temporary income replacement following a job loss, and social assistance (i.e., welfare benefits) that provide long-term support to low income, wealth-poor individuals. In our analysis, we consider a taxand-transfer system that includes all of these features and, to align with our data, is based in the German system. Sections 2.1 and 2.2 provide more details about the tax and transfer programs that we consider. 


\section{$2.1 \quad$ Taxes}

Individuals face three annual taxes: a tax on annual labor earnings; a tax on annual interest income; and a social security tax on annual labor earnings. Figure 1 shows the tax on annual labor earnings and the associated average tax rate. This tax is strongly progressive on an annual basis: the average tax rate varies from $0 \%$ for individuals with labor earnings below 8,584 euros per year to over $30 \%$ for individuals with labor earnings of 70,000 euros per year. The tax on annual interest income is a flat rate tax of $25 \%$ on interest income above an exemption and, therefore, is also progressive. The social security tax is a flat-rate tax of around $20 \%$ on annual labor earnings below a cap. Appendix II provides further details about taxes. For the population that we study, the tax on annual labor earnings accounts for the majority of all tax payments.

Figure 1: Tax on annual labor earnings
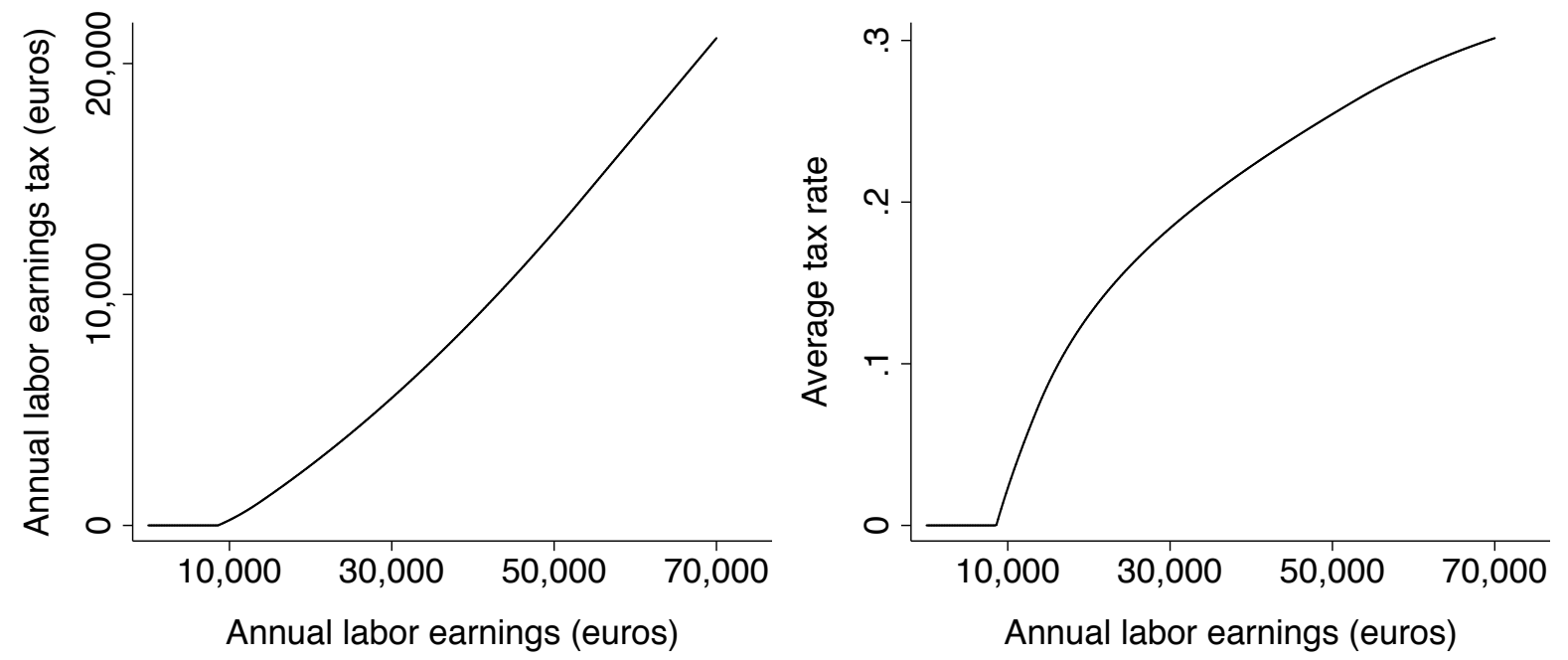

\subsection{Transfers}

Transfers include unemployment insurance, disability benefits and social assistance. ${ }^{1}$

Unemployment insurance: An individual who enters nonemployment from employment receives unemployment insurance for one year. Unemployment insurance is equal to sixty percent of the individual's after-tax labor earnings in the year before he entered nonemployment.

Disability benefits: An individual in bad health may choose to enter disability-based retirement, irrespective of his age. Once in disability-based retirement, an individual receives disability benefits each year for the reminder of his life. Disability benefits reflect wages and employment behavior prior to retirement, and include an experience credit of one

\footnotetext{
${ }^{1}$ The model also includes pension benefits, which are paid to individuals in old-age retirement. Pension benefits are discussed in Appendix I.
} 
year for each year that the individual entered disability-based retirement before age 60 years. $^{2}$

Social assistance: Social assistance guarantees every individual a minimum annual income: if an individual's combined annual income from labor earnings, interest income, unemployment insurance and disability benefits is below the annual minimum income guaranteed by social assistance then the individual receives a social assistance transfer to increase his annual income to the level of the annual minimum income guarantee. The annual minimum income guarantee ranges from 8,340 euros per year if the individual has no assets to zero if the individual is sufficiently wealthy. In more detail, the annual minimum income guaranteed by social assistance is equal to:

$$
\max \left\{8,340-\max \left\{A_{i, t}-10,000-500 \times(t-20), 0\right\}, 0\right\},
$$

where $A_{i, t}$ denotes the individual's assets at age $t$. Intuitively, the annual minimum income guarantee is adjusted downwards by one euro for each euro of assets in excess of an agespecific disregard. The age-specific disregard starts at 10,000 euros for an individual who is aged 20 years and increases by 500 euros with each year of age.

\section{A model of lifetime income}

Our analysis of the effect of taxes and transfers on the inequality of lifetime income has three requirements. First, we need individual-level information about lifetime earnings and lifetime income. To calculate these lifetime quantities, we need information about earnings, taxes, and transfers in each year of the life cycle.

Second, we need to link the individual-level measures of lifetime earnings and lifetime income to individuals' skill endowments, that is those immutable individual attributes that are allotted early in life and that affect earnings and income over the life cycle. Using this connection, we can separate the inequality in lifetime earnings and lifetime income that is attributable to individuals' skill endowments ('between-endowment inequality') from the inequality in lifetime earnings and lifetime income that is due to shocks, such as job loss and health shocks, that vary among individuals with the same endowments ('within-endowment inequality'). This, in turn,

${ }^{2}$ An individual who enters retirement in bad health at age $R$ receives an annual disability benefit of:

$$
\mathrm{DB}_{i, t}=\alpha \times \bar{W}_{i, R} \times \text { DBPenalty }_{R} \times\left(\operatorname{Exper}_{i, R}+\text { Credit }_{R}\right),
$$

where $\alpha$ is a parameter that controls the generosity of disability benefits, $\bar{W}_{i, R}$ is the individual's disabilitybenefit-eligible annual earnings averaged over all years of employment prior to retirement, DBPenalty $R$ is a penalty that reduces the individual's annual disability benefit by $3.6 \%$ for each year that he retired before the age of 63 years (up to a maximum reduction of 10.8\%), $\operatorname{Exper}_{i, R}$ denotes the individual's experience at retirement (i.e., the number of years that the individual was employed during his life), and Credit $R$ is an experience credit of one year for each year that the individual is entered disability-based retirement before the age of 60 years. Only annual earnings below 58,404 euros are considered when calculating disability benefits. 
allows us to distinguish between the insurance and redistributive effects of taxes and transfers: taxes and transfers are redistributive on a lifetime basis if the between-endowment inequality of lifetime income is less than the between-endowment inequality of lifetime earnings, and taxes and transfers insure lifetime earnings risk if the within-endowment inequality of lifetime income is less than the within-endowment inequality of lifetime earnings.

Third, to understand how taxes and transfers insure specific risks to lifetime earnings, such as the risk of job loss, we need to derive lifetime earnings and lifetime income when individuals face counterfactual risk environments. To do this, we must account for how behavior responds to changes in risk. Behavioral adjustments in response to changes in risk may have important implications for inequality: individuals may, for example, respond to an increase in the probability of job separation by increasing labor supply, thereby limiting how much of the extra job separation risk passes through to the inequality of lifetime income.

We derive the required information about earnings, income, skill endowments and labor supply from a dynamic life-cycle model. According to this model, in each year of the life cycle, each individual chooses a labor supply state $(l)$ and a level of consumption $(c)$ to maximize the discounted present value of his lifetime utility. The model includes three mutually exclusive labor supply states: employment, nonemployment, and retirement. ${ }^{3}$ Inequality in lifetime earnings may arise from differences between individuals' endowments or from different realizations of life-cycle risks. In terms of risks, we consider employment risk (from job separation risk and job offer risk) and health risk. Importantly, the model includes taxes and transfers. We can therefore use the model to explore how the tax-and-transfer system insures lifetime earnings risk and how it redistributes lifetime earnings. The model is described in Sections 3.1-3.8.

\subsection{Endowments}

Each individual is endowed with a level of education and a productive ability. Individual $i$ 's educational endowment, Educ $_{i} \in\{7, \ldots, 18\}$, is equal to his years of schooling. ${ }^{4}$ Meanwhile, in the primary model specification, we distinguish three levels of productive ability. The individual's endowment of productive ability is given by $\eta_{i} \in\left\{\eta_{1}, \eta_{2}, \eta_{3}\right\} .^{5}$ A proportion $\rho_{j}$ of individuals are productive ability type $j$ where $\sum_{j=1}^{3} \rho_{j}=1$. Combining the eleven possible values of education with the three productive ability types gives a total of thirty-three distinct endowment groups. As we explain below, the endowments may affect health risk, employment risk, and wages over the life cycle. In this way, the model may generate between-endowment inequality in lifetime earnings and lifetime income.

We also consider two extended specifications, one that includes four productive ability types

\footnotetext{
${ }^{3}$ Employment corresponds to 40 hours of work per week; this is the median hours of work per week for employees in the estimation sample. Nonemployment is defined to include individuals who are not willing to work at their market wage and individuals who are willing to work at their market wage but do not receive a job offer.

${ }^{4}$ The individual first enters the labor force at the later of age twenty and age Educ $i+8$ years.

${ }^{5}$ We impose $\eta_{1}>\eta_{2}>\eta_{3}$. This is for identification and is without loss of generality.
} 
and another that includes five productive ability types. Appendix V shows that our results on the insurance and redistributive effects of taxes and transfers are robust to allowing four or five productive ability types, instead of the three types that are allowed in the primary specification.

\subsection{Health risk}

An individual's health status is either good or bad. Individuals are in good health when they first enter the labor market. Health then evolves stochastically over the life cycle: each year, an individual in good health may be subject to a negative health shock, which transitions him into bad health, while an individual in bad health may be subject to a positive health shock, which transitions him into good health. The health transition probabilities depend on age, previous health status and education, and they are given by the following nonparametric model:

$$
\operatorname{Prob}\left(\text { Health }_{i, t}=1\right)=G_{t}\left(1\left(\text { Educ }_{i} \geq 12\right), \text { Health }_{i, t-1}\right),
$$

where Health $_{i, t}$ is an indicator of the individual being in good health at age $t, 1\left(\right.$ Educ $\left._{i} \geq 12\right)$ is an indicator of the individual having at least twelve years of education, which we refer to as high education, and $G_{t}(\cdot)$ is an age-dependent nonparametric function. Section 4.3 provides further details about the nonparametric model of health risk.

\subsection{Employment risk}

Employment is feasible only if the individual receives a job offer in the current year. The likelihood of receiving a job offer in the current year depends on the individual's employment status in the previous year. An individual who was employed in the previous year receives a job offer in the current year provided that they are not subject to a job separation, which occurs with probability $\Phi_{i, t}^{s}$. An individual who was nonemployed in the previous year receives a job offer in the current year with probability $\Phi_{i, t}^{o}$. Retired individuals do not receive job offers. The job separation and job offer probabilities are given by:

$$
\begin{gathered}
\Phi_{i, t}^{j}=\Lambda\left(\phi_{1}^{j}+\phi_{2}^{j} 1\left(\operatorname{Educ}_{i} \geq 12\right)+\phi_{3}^{j} \operatorname{Health}_{i, t}+\phi_{4}^{j} 1(t \geq 50)+\right. \\
\left.\phi_{5}^{j} 1(t \geq 55)+\phi_{6}^{j} 1(t \geq 60)\right) \text { for } j \in\{s, o\}
\end{gathered}
$$

where $\Lambda(\cdot)$ denotes the logistic distribution function.

\subsection{Retirement}

An individual may retire only if he meets certain health- or age-based criteria. In particular, an individual may retire only if he is in bad health (disability-based retirement) or if he is age 63 years or older (old-age retirement). Retirement is compulsory at age 65 years, and once retired the individual remains retired until the end of the life cycle at age 78 years. 


\subsection{Wages and labor earnings}

The log hourly wage is given by:

$$
\begin{aligned}
\log \left(\text { Wage }_{i, t}\right)= & \psi_{1} \text { Educ }_{i}+\left(\psi_{2} \text { Exper }_{i, t}+\psi_{3} \operatorname{Exper}_{i, t}^{2}\right) \times 1\left(\text { Educ }_{i}<12\right)+ \\
& \left(\psi_{4} \text { Exper }_{i, t}+\psi_{5} \text { Exper }_{i, t}^{2}\right) \times 1\left(\text { Educ }_{i} \geq 12\right)+\psi_{6} \text { Health }_{i, t}+\eta_{i}
\end{aligned}
$$

where Exper $_{i, t}$ denotes experience, defined as the total number of years that the individual was employed during his life prior to the current year. ${ }^{6}$ Since employment entails 40 hours of work per week (see footnote 3 ), the annual labor earnings of employed individual $i$ at age $t$ are equal to Wage $_{i, t} \times 40 \times 52$.

\subsection{Inter-temporal budget constraint}

Assets, $A_{i, t}$ are accumulated according to:

$$
A_{i, t}=(1+r) A_{i, t-1}+\text { LaborEarnings }_{i, t}-\text { Taxes }_{i, t}+\operatorname{Transfers}_{i, t}-c_{i, t},
$$

where $c_{i, t}$ denotes the annual consumption of individual $i$ at age $t$ and $r$ denotes the real interest rate (assumed to be equal to 0.02). The term $r A_{i, t-1}$ in (6) thus denotes individual $i$ 's annual interest income at age $t$.

\subsection{Consumption and preferences}

Each year, the individual chooses a level of saving, and thus a level of consumption, from a finite set of alternatives. In more detail, an individual's consumption at age $t$ is equal to his annual income minus his annual savings. An employed individual chooses annual savings (in euros) from the set $\{0,500,1000,1500,2500,5000,7500,10000\}$. A nonemployed individual chooses annual savings (in euros) from the set $D_{i, t}+\{0,500,1000,1500,2500\}$, where $-D_{i, t}$ is the level of dis-saving that is required to increase the individual's annual after-tax-and-transfer earnings to the minimum income level that social assistance guarantees to asset poor households (i.e., 8,340 euros per year, see Section 2.2). A retired individual dis-saves the annuity value of his wealth.

Individuals derive utility from consumption and leisure. The individual's per-period utility

\footnotetext{
${ }^{6}$ When estimating the model we also include wage measurement error, which adds noise to sample wages but does not affect the wages that individuals receive. Specifically, we assume that sample log wages are given by $\log \left(\mathrm{Wage}_{i, t}\right)+\mu_{i, t}$, where $\mu_{i, t} \sim \mathbb{N}\left(0, \sigma_{\mu}^{2}\right)$ and is independent over individuals and years.
} 
function is given by:

$$
\mathrm{U}\left(c_{i, t}, l_{i, t}, \epsilon_{i, t}\right)= \begin{cases}\alpha_{1} \frac{c_{i, t}^{1-\gamma}}{1-\gamma}+\epsilon\left(c_{i, t}, l_{i, t}\right) & \text { if nonemployed or retired } \\ \alpha_{1} \frac{\left(\left(1-\alpha_{2}\right) c_{i, t}\right)^{1-\gamma}}{1-\gamma}+\epsilon\left(c_{i, t}, l_{i, t}\right) & \text { if employed }\end{cases}
$$

where $\alpha_{1}$ is the weight given to the systematic utility from consumption and leisure relative to the preference shocks, $\left(1-\alpha_{2}\right) \in(0,1]$ is the share of consumption enjoyed if employed, i.e., $\alpha_{2}$ is the disutility of working, and $\gamma \equiv 0.5$ is the coefficient of relative risk aversion. The preference shocks, $\epsilon_{i, t}\left(c_{i, t}, l_{i, t}\right)$, are assumed to be type-1 extreme value distributed and independent over consumption choices and labor supply states. $\epsilon_{i, t}$ is a vector that contains all of the individual's age- $t$ preference shocks.

\subsection{Optimal behavior}

The individual's optimal consumption and labor supply choice at age $t$ is given by:

$$
\left\{c_{i, t}^{*}, l_{i, t}^{*}\right\}=\max _{\{c, l\} \in \mathbb{D}\left(\mathbf{s}_{t}\right)}\left\{\mathrm{U}\left(c, l, \epsilon_{i, t}\right)+\beta \mathrm{E}_{t}\left[V_{t+1}\left(\mathbf{s}_{i, t+1}\right) \mid \mathbf{s}_{i, t}, c, l\right]\right\} .
$$

In the above, $\beta \equiv 0.98$ is the discount factor, $\mathbb{D}\left(\mathbf{s}_{t}\right)$ is the set of choices that is available to the individual at age $t$ (the choice set is determined by job separations, job offers, wealth and the age- and health-based restrictions on eligibility for retirement), $V_{t+1}\left(\mathbf{s}_{i, t+1}\right)$, is the value function, i.e., the maximal expected discounted present value of lifetime utility at age $t+1$, and $\mathbf{s}_{i, t}$ denotes the state variables. The state variables are as follows:

$$
\mathbf{s}_{i, t} \equiv\left\{\operatorname{Educ}_{i}, \eta_{i}, t, \operatorname{Health}_{i, t}, \operatorname{Exper}_{i, t}, A_{i, t}, l_{i, t-1}, \epsilon_{i, t}, \mathrm{JS}_{i, t}, \mathrm{JO}_{i, t}\right\}
$$

where $\mathrm{JS}_{i, t}$ and $\mathrm{JO}_{i, t}$ are indicators of the individual receiving, respectively, a job separation and a job offer at age $t$.

\section{Parameter estimates, model fit and validation}

We estimate the parameters of the life-cycle model using an unbalanced annual panel sample of men from the German Socio-Economic Panel (Wagner et al., 2007; Socio-Economic Panel, 2013). The estimation sample contains 3,154 distinct individuals and a total of 15,862 individualyear observations from the years 2004-2012. Appendix III describes the sample in more detail.

We estimate the model in two stages. First, we estimate the health transition probabilities given by (3). Specifically, we compute the empirical probability of good health for each combination of age, previous health status, and educational category (less than twelve years of 
education or at least twelve years of education). We then smooth the age profiles of the empirical health probabilities using a Nadaraya-Watson kernel regression (Nadaraya, 1964, Watson, 1964) with an epanechnikov kernel and the rule-of-thumb bandwidth (Fan and Gijbels, 1996). In the second stage of the estimation, we use a Maximum Likelihood procedure that targets the patterns of labor supply and wages that we observe in the estimation sample to estimate the parameters that appear in the utility function, the wage equation, and the job offer and job separation probabilities. Appendix IV explains how we approximate the value function, presents the likelihood function, and describes how we maximize the likelihood function.

Sections 4.1-4.3 discuss the parameter estimates, Section 4.4 shows that the estimated model has good in-sample fit, and Section 4.5 validates the estimated model by comparing estimates of inequality obtained from the model to corresponding estimates derived from a comparable administrative dataset that was not used for estimation.

\subsection{Preferences and wages}

Panel I of Table 1 reports our estimates of the parameters of the utility function. We estimate the disutility of employment to be $38 \%$ of consumption. Panel II of Table 1 reports our estimates of the parameters of the wage equation. To aid interpretation, Figure 2 illustrates how the wage equation parameter estimates translate into wage profiles for six different endowment groups. We find that wages vary strongly with both parts of individuals' endowments (education and productive ability). We also find positive returns to experience (with a minor exception for individuals with close to the maximal level of experience). However, for the purpose of interpreting our later results, it is important to note that the variation in wages with experience within an endowment group is small and is much lower than the variation in wages between different endowment groups. The effect of health status on wages is negligible in magnitude (being in good health instead of bad health increases the wage by less than 1\%). Panel III of Table 1 shows that we estimate that $29 \%$ of individuals are endowed with high productive ability (type 1), $47 \%$ are endowed with medium productive ability (type 2), and the remaining $25 \%$ are endowed with low productive ability (type 3 ). 
Table 1: Parameters of the utility function, wage equation and type probabilities

\begin{tabular}{llcc}
\hline \hline & & Estimate & Standard error \\
\hline & Panel I: Utility function & \\
$\alpha_{1}$ & (Weight on utility from consumption and leisure) & 3.498 & 0.0827 \\
$\alpha_{2}$ & (Disutility of employment) & 0.380 & 0.0082 \\
& & & \\
\hline
\end{tabular}

Panel II: Wage equation

$\begin{array}{llrl}\eta_{1} & (\text { Intercept for productive ability type } 1) & 2.083 & 0.0112 \\ \eta_{2} & (\text { Intercept for productive ability type } 2) & 1.733 & 0.0112 \\ \eta_{3} & (\text { Intercept for productive ability type } 3) & 1.342 & 0.0113 \\ \psi_{1} & (\text { Educ } / 10) & 0.532 & 0.0067 \\ \psi_{2} & (\text { Exper } / 10 \times 1(\text { Educ }<12)) & 0.230 & 0.0055 \\ \psi_{3} & (\text { Exper } / 10 \times 1(\text { Educ } \geq 12)) & 0.277 & 0.0058 \\ \psi_{4} & \left(\text { Exper }^{2} / 100 \times 1(\text { Educ }<12)\right) & -0.036 & 0.0012 \\ \psi_{5} & \left(\text { Exper }^{2} / 100 \times 1(\text { Educ } \geq 12)\right) & -0.044 & 0.0013 \\ \psi_{6} & (\text { Health }) & 0.009 & 0.0040\end{array}$

Panel III: Productive ability type probabilities

$\begin{array}{llll}\rho_{1} & \text { (Fraction of productive ability type 1) } & 0.287 & 0.0095 \\ \rho_{2} & \text { (Fraction of productive ability type 2) } & 0.466 & 0.0108\end{array}$

Notes: 'Educ' is years of education, 'Exper' is years of experience, and 'Health' is an indicator of good health. Standard errors were derived from the Hessian of the log likelihood function at its maximum. The estimate of the fraction of productive type 3 is equal to 0.247 . The estimate of the standard deviation of the measurement error in wages is equal to 0.189 (standard error $=0.0008$ ).

Figure 2: Estimated wage profiles

(a) 11 years of education, good health

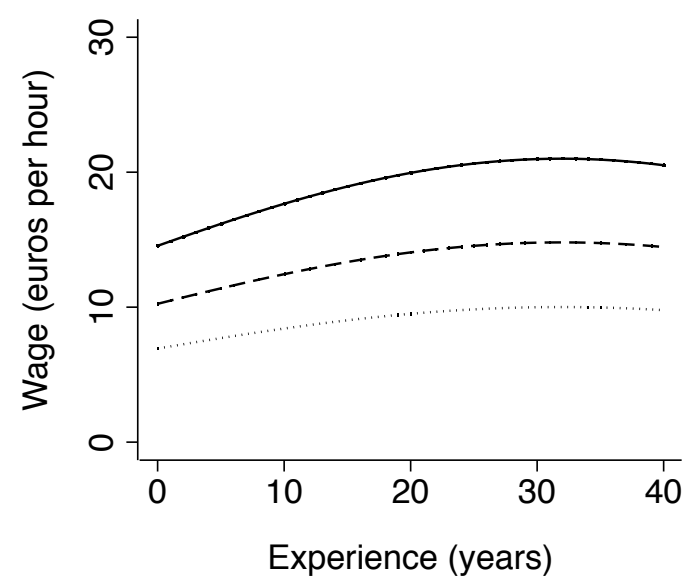

(b) 14 years of education, good health

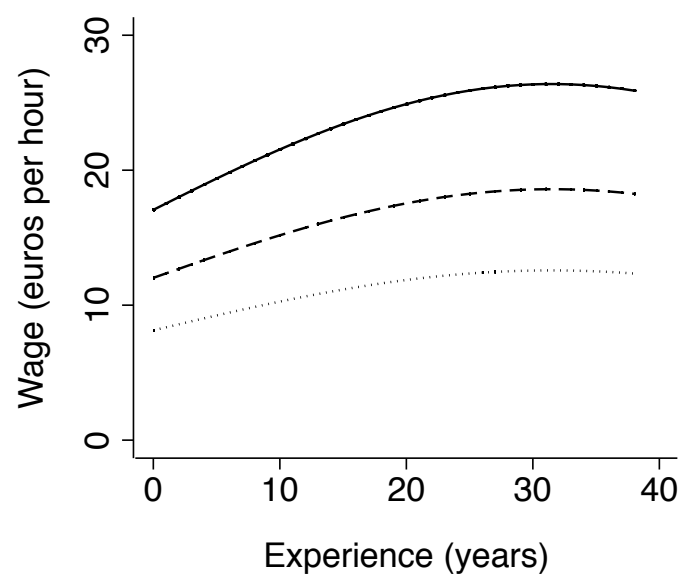

Productive ability type 1

Productive ability type 2

Productive ability type 3

Notes: Wage profiles were calculated using the parameter estimates shown in Panel II of Table 1. 


\subsection{Employment risk}

Table 2 shows the estimated job offer and job separation probabilities, which together describe employment risk. Conditional on education, individuals in bad health and older individuals face higher job separation probabilities and lower job offer probabilities than, respectively, individuals in good health and younger individuals. Conditional on health status and age, the job offer and job separation probabilities decrease with education, which implies that highly educated individuals are both relatively unlikely to be forced out of employment and face a relatively long expected duration before receiving a job offer.

Table 2: Job offer and job separation probabilities

\begin{tabular}{|c|c|c|c|c|c|}
\hline & & Age $<50$ & $50 \leq$ Age $<55$ & $55 \leq$ Age $<60$ & Age $\geq 60$ \\
\hline \multicolumn{6}{|c|}{ Panel I: Job offer probabilities } \\
\hline \multirow[t]{2}{*}{ Educ $<12$} & Bad health & $\begin{array}{c}0.083 \\
(0.0087)\end{array}$ & $\begin{array}{c}0.017 \\
(0.0039)\end{array}$ & $\begin{array}{c}0.016 \\
(0.0043)\end{array}$ & $\begin{array}{c}0.007 \\
(0.0018)\end{array}$ \\
\hline & Good health & $\begin{array}{c}0.534 \\
(0.0198)\end{array}$ & $\begin{array}{c}0.182 \\
(0.0238)\end{array}$ & $\begin{array}{c}0.169 \\
(0.0251)\end{array}$ & $\begin{array}{c}0.076 \\
(0.0147)\end{array}$ \\
\hline \multirow[t]{2}{*}{ Educ $\geq 12$} & Bad health & $\begin{array}{c}0.058 \\
(0.0062)\end{array}$ & $\begin{array}{c}0.012 \\
(0.0027)\end{array}$ & $\begin{array}{c}0.011 \\
(0.0029)\end{array}$ & $\begin{array}{c}0.004 \\
(0.0012)\end{array}$ \\
\hline & Good health & $\begin{array}{c}0.436 \\
(0.0158)\end{array}$ & $\begin{array}{c}0.130 \\
(0.0184)\end{array}$ & $\begin{array}{c}0.120 \\
(0.0187)\end{array}$ & $\begin{array}{c}0.053 \\
(0.0102)\end{array}$ \\
\hline \multicolumn{6}{|c|}{ Panel II: Job separation probabilities } \\
\hline \multirow[t]{2}{*}{ Educ $<12$} & Bad health & $\begin{array}{c}0.087 \\
(0.0060)\end{array}$ & $\begin{array}{c}0.089 \\
(0.0107)\end{array}$ & $\begin{array}{c}0.119 \\
(0.0132)\end{array}$ & $\begin{array}{c}0.313 \\
(0.0242)\end{array}$ \\
\hline & Good health & $\begin{array}{c}0.026 \\
(0.0017)\end{array}$ & $\begin{array}{c}0.029 \\
(0.0032)\end{array}$ & $\begin{array}{c}0.040 \\
(0.0044)\end{array}$ & $\begin{array}{c}0.124 \\
(0.0107)\end{array}$ \\
\hline \multirow[t]{2}{*}{ Educ $\geq 12$} & Bad health & $\begin{array}{c}0.057 \\
(0.0058)\end{array}$ & $\begin{array}{c}0.059 \\
(0.0111)\end{array}$ & $\begin{array}{c}0.079 \\
(0.0140)\end{array}$ & $\begin{array}{c}0.225 \\
(0.0270)\end{array}$ \\
\hline & Good health & $\begin{array}{c}0.019 \\
(0.0014)\end{array}$ & $\begin{array}{c}0.019 \\
(0.0031)\end{array}$ & $\begin{array}{c}0.026 \\
(0.0042)\end{array}$ & $\begin{array}{c}0.083 \\
(0.0104)\end{array}$ \\
\hline
\end{tabular}

Notes: 'Educ' is years of education. Reported probabilities were obtained by evaluating (4) at the Maximum Likelihood parameter estimates. Standard errors are given in parentheses and were calculated using the delta rule.

\subsection{Health risk}

Figure 3 shows the estimated profiles of health risk over the life cycle. Education is an important determinant of health. In particular, at every age, having at least twelve years of education 
decreases the likelihood of a bad health shock (i.e., a transition from good to bad health) and increases the likelihood of a good health shock (i.e., a transition from bad to good health). Reflecting a general deterioration in health status over the life cycle, the probability of a bad health shock increases with age and the probability of a good health shock decreases with age for both educational groups.

Figure 3: Health risk
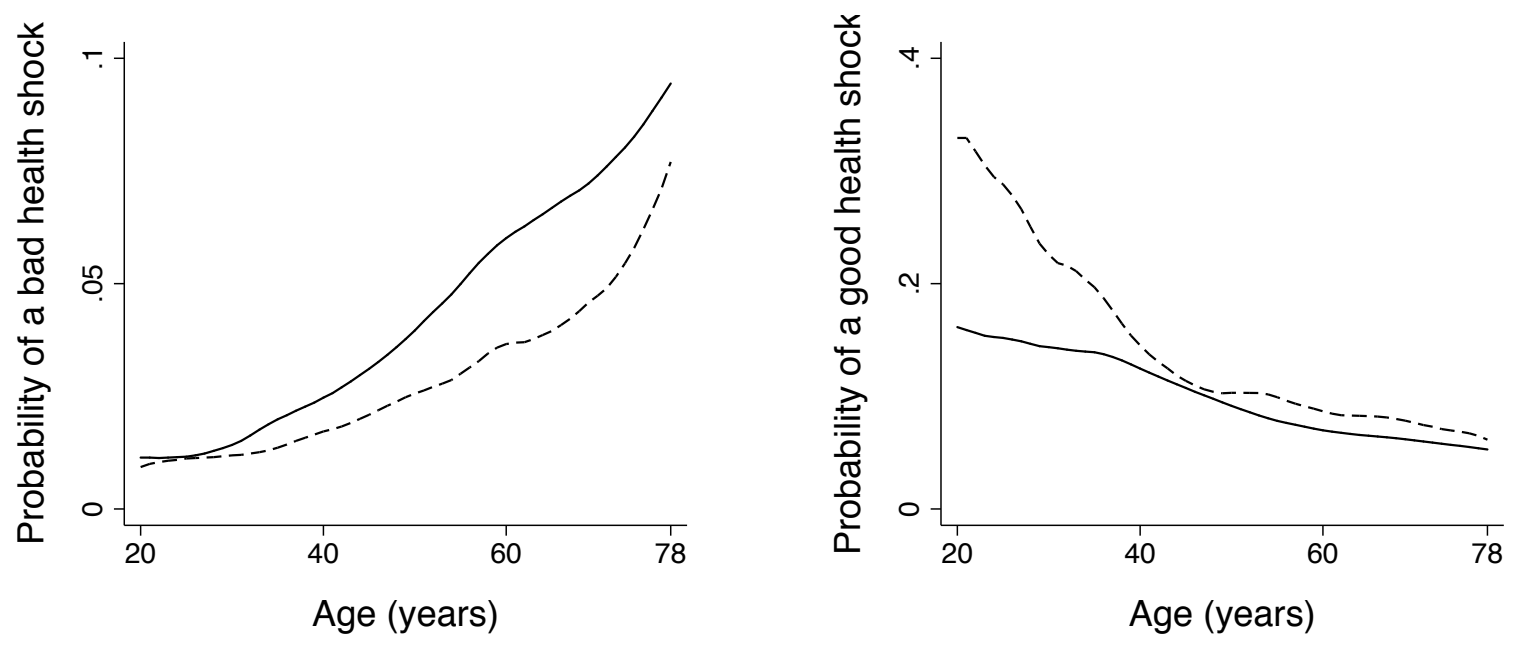

Educ $<12$ Educ $\geq 12$

Notes: 'Educ' is years of education. Illustrated probabilities were obtained using the nonparametric estimation method described in the second paragraph of Section 4.

\subsection{In-sample fit}

Figures 4(a)-(c) shows that the estimated model captures accurately the life-cycle profiles of employment and wages. Figure 5 shows that the estimated model fits the distribution of wages, both overall and when we split the sample based on years of education. Figure 4(d) shows that the model fits the profile of wealth over the life cycle. This provides further support for the model specification, particularly since estimation procedure does not directly target wealth. ${ }^{7}$

Given that we use the estimated model to study the inequality of lifetime earnings and lifetime income, it is important that the estimated life-cycle model replicates accurately the persistence in labor supply and earnings that we see in the estimation sample. We explore the ability of the estimated model to fit the observed persistence in employment, nonemployment and retirement by comparing the distributions of individual-level measures of persistence across the estimation sample and a sample simulated using the estimated model (the notes to Figure 4 describe the simulated sample). We define employment persistence for an individual as the fraction of an individual's time in the sample during which he was employed (e.g., employment persistence is 0.33 for an individual who was in the sample for 6 years and was employed for 2

\footnotetext{
${ }^{7}$ The ability of the model to replicate the observed profile of wealth also supports our assumptions about risk aversion and the discount factor.
} 
Figure 4: Observed and predicted age profiles of employment, wages and wealth

(a)

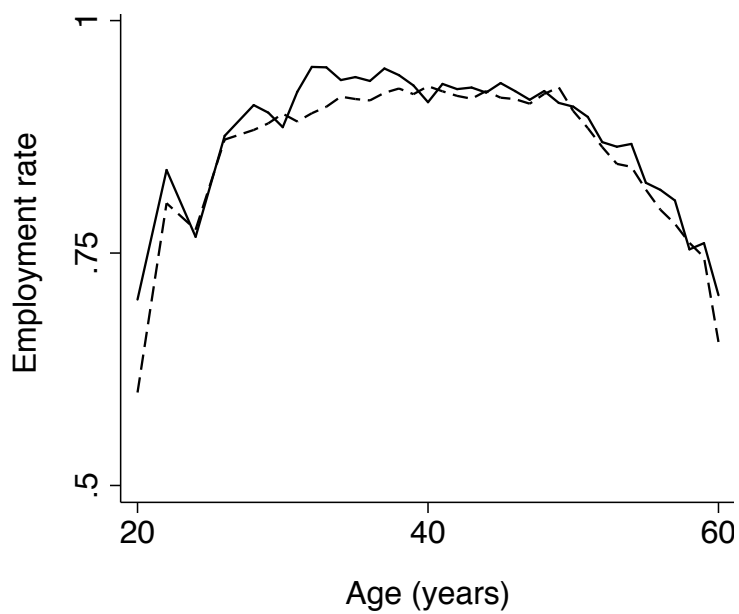

(c)

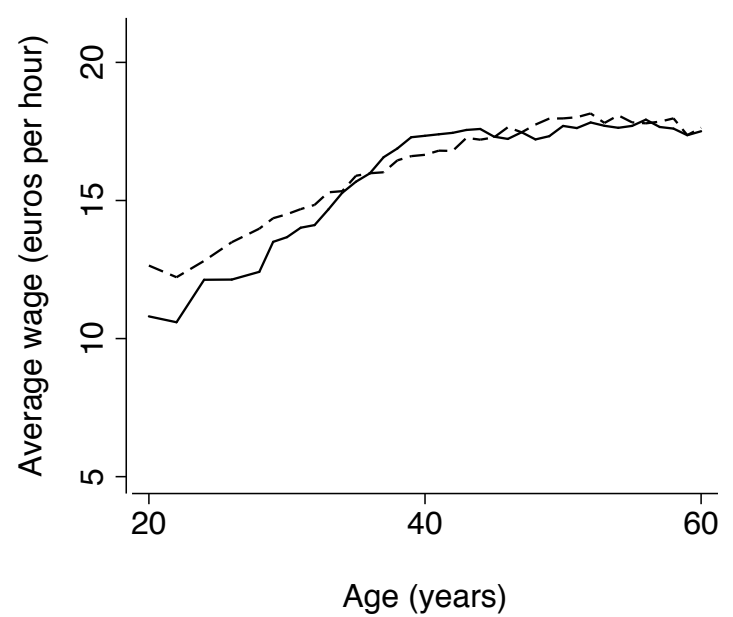

(b)

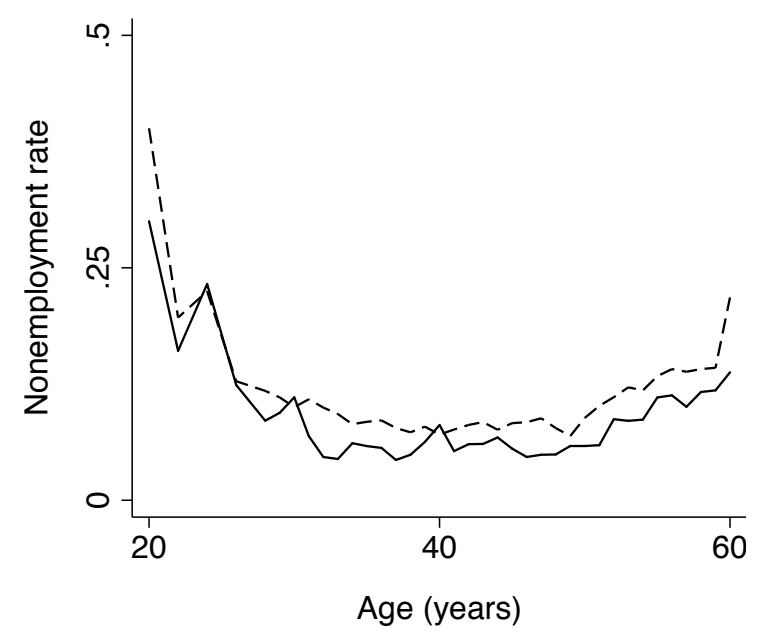

(d)

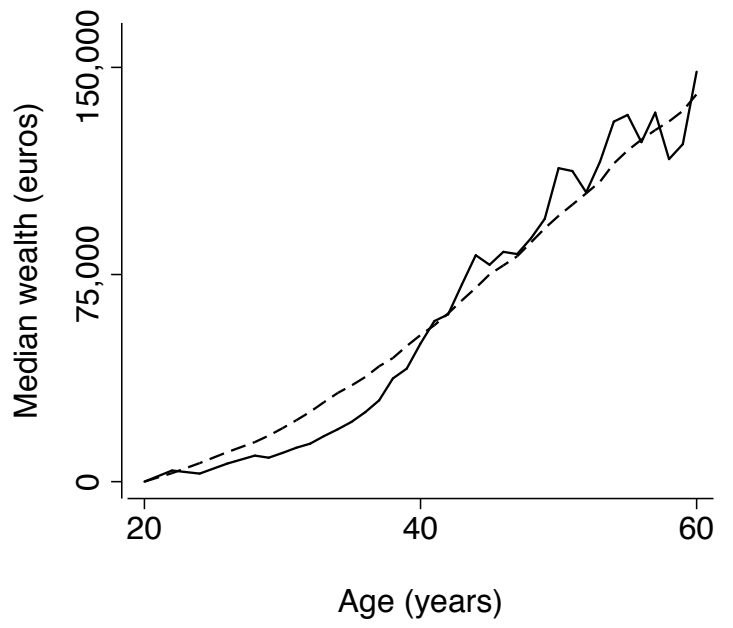

Notes: Observed values were calculated using the estimation sample, which contains 3,145 individuals and 15,862 individual-year observations. Predicted values were calculated using a simulated sample. The simulated sample was constructed by using the estimated life-cycle model to simulate three lifecycle trajectories of labor supply, health, wages and wealth for each of the 3,145 individuals in the estimation sample. Each individual in the simulated sample was endowed with the level of education observed for the individual in the estimation sample and a productive ability drawn from the estimated distribution of productivity ability types (see Panel III of Table 1). Simulated wage values include measurement error (see footnote 6 and the notes to Table 1). To ensure comparability with the estimation sample, predicted values were calculated using only simulated outcomes from the age values at which the individual was observed in the estimation sample, and when calculating predicted wage values we further restrict the simulated sample by including only individuals who are employed in the simulation. 
Figure 5: Observed and predicted distributions of wages

(a) All

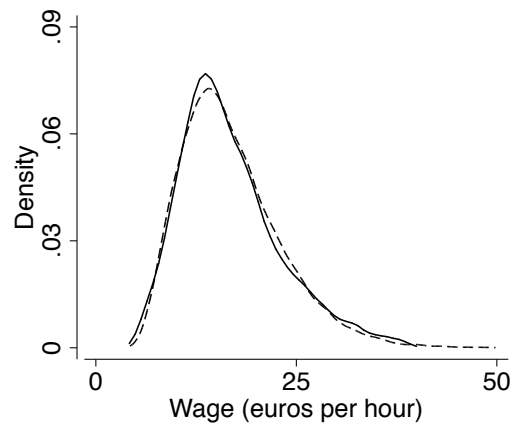

(b) Educ $\geq 12$

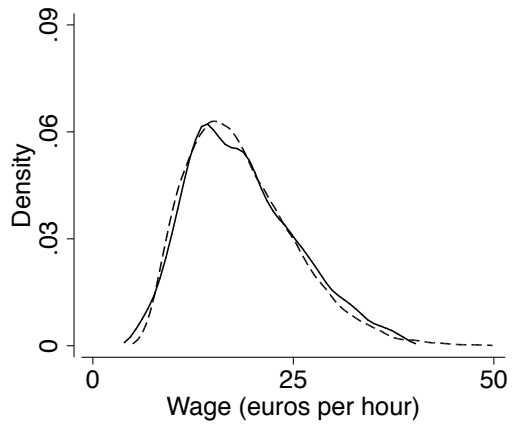

Observed ----- Predicted (c) Educ $<12$

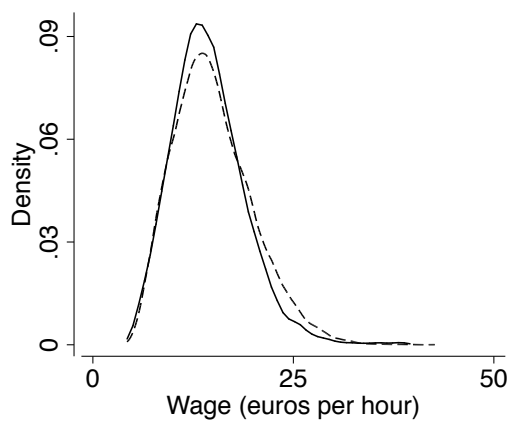

Notes: 'Educ' is years of education. Observed values were calculated using the estimation sample. Predicted values were calculated using a simulated sample (the notes to Figure 4 describe the simulated sample). To ensure comparability with the estimation sample, predicted values were calculated using only simulated outcomes from the age values at which the individual was observed in the estimation sample. For both samples, we focus on employed individuals aged 20-59 years inclusive.

Table 3: Observed and predicted persistence in labor supply

\begin{tabular}{|c|c|c|c|c|c|c|}
\hline \multirow{3}{*}{$\begin{array}{c}\text { Level of } \\
\text { persistence }\end{array}$} & \multicolumn{6}{|c|}{ Fraction of individuals } \\
\hline & \multicolumn{2}{|c|}{ Employment persistence } & \multicolumn{2}{|c|}{ Nonemployment persistence } & \multicolumn{2}{|c|}{ Retirement persistence } \\
\hline & Observed & Predicted & Observed & Predicted & Observed & Predicted \\
\hline$=0$ & 0.09 & 0.06 & 0.82 & 0.82 & 0.95 & 0.98 \\
\hline$\leq 0.25$ & 0.10 & 0.08 & 0.88 & 0.87 & 0.96 & 0.98 \\
\hline$\leq 0.5$ & 0.12 & 0.12 & 0.93 & 0.92 & 0.97 & 0.99 \\
\hline$\leq 0.75$ & 0.17 & 0.17 & 0.94 & 0.94 & 0.97 & 0.99 \\
\hline
\end{tabular}

Notes: Observed values were calculated using the estimation sample. Predicted values were calculated using a simulated sample (the notes to Figure 4 describe the simulated sample). To ensure comparability with the estimation sample, predicted values were calculated using only simulated outcomes from the age values at which the individual was observed in the estimation sample. Persistence in a particular labor market state is measured at the individual level and is defined as the fraction of individual's time in the sample during which he was observed in that state. For both samples, persistence measures were calculated using individuals aged 20-59 years inclusive. 
of these years). We use the same method to derive measures of persistence in nonemployment and persistence in retirement. Table 3 shows that the estimated model reproduces the patterns of persistence in employment, nonemployment and retirement that we observe in the estimation sample. For example, $13 \%$ of individuals in the estimation sample are employed for $50 \%$ or fewer of the years that they were in the sample, compared to the model prediction of $12 \%$. Similarly, among individuals in the estimation sample, $82 \%$ were never observed in nonemployment and 95\% were never observed in retirement, while the model predicts $81 \%$ and $97 \%$, respectively.

Figure 6: Observed and predicted persistence in labor earnings

(a) All

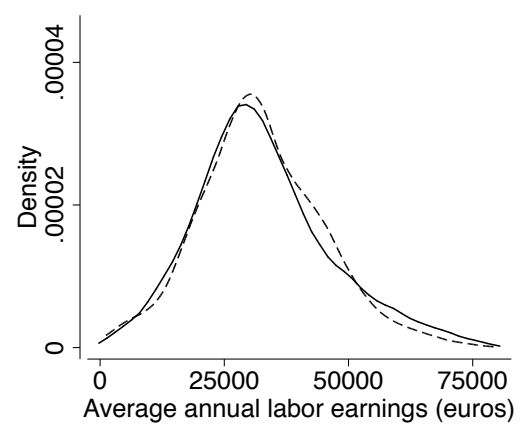

(b) Educ $\geq 12$

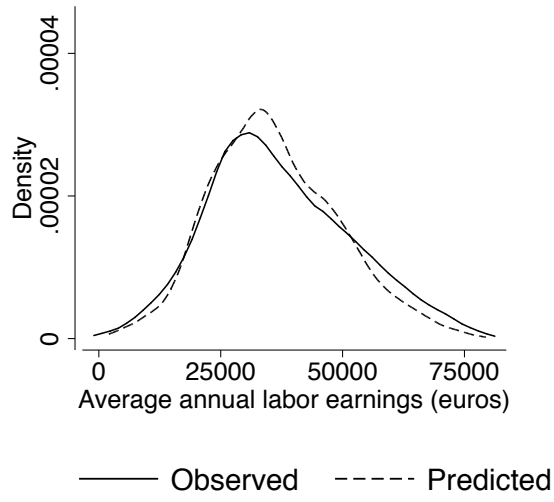

(c) Educ $<12$

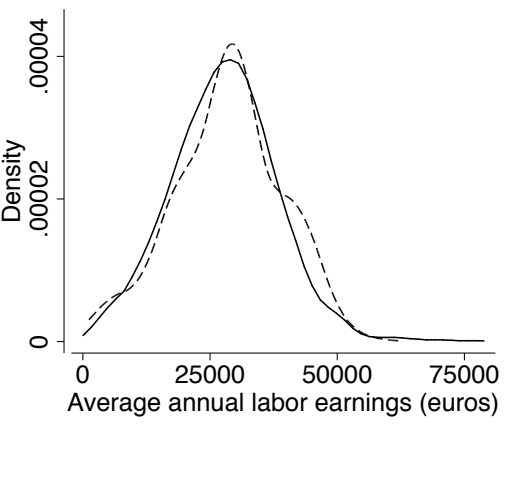

Notes: 'Educ' is years of education. 'Average annual labor earnings' is the individual-level average of annual labor earnings over the years that the individual was in the sample. Individuals with zero average annual labor earnings (i.e., those individuals who never worked during the sample period) are excluded from all figures. Across all individuals, the observed and predicted fractions of individuals with zero average annual labor earnings are 0.089 and 0.064 , respectively. The corresponding figures are 0.072 and 0.042 for individuals with at least twelve years of education and 0.110 and 0.083 for individuals with fewer than twelve years of education. Also see the notes to Figure 5.

Similarly, we document the ability of the estimated model to fit the observed persistence in labor earnings. In particular, for each individual, we calculate the average of his annual labor earnings over the years during which he was in the sample and employed. We refer to this as the individual-level average of annual earnings. We then compare the distributions of the individual-level average of annual labor earnings across the estimation sample and a sample simulated using the estimated model (the notes to Figure 4 describe the simulated sample). Note, the individual-level average of annual labor earnings combines information about employment persistence over the life cycle with information about wages, and it therefore provides a summary measure of individual-level labor earnings dynamics. Figure 6 shows that the estimated model fits the distribution of individual-level average of annual labor earnings observed in the estimation sample. Also, when we split the samples based on whether an individual has less than twelve years of education or at least twelve years of education, the model continues to fit the distribution of average annual labor earnings within each educational category. 


\subsection{Validation}

We validate the estimated model by comparing the labor earnings inequality implied by the estimated model with the labor earnings inequality observed in a comparable sample that was not used for estimation. In particular, we use the estimated model to simulate a sample of life-cycle labor earnings profiles. We then compare the inequality of annual and lifetime labor earnings in the simulated sample to Bönke et al. (2015)'s calculations of the inequality of annual and lifetime labor earnings based on a sample of lifetime labor earnings histories taken from administrative social security records for Germany. Importantly, the sample selection criteria used by Bönke et al. (2015) closely match the rules used for constructing our estimation sample (see Appendix III): both samples exclude civil servants, self-employed individuals, East Germans, and women. Our simulated sample and Bönke et al. (2015)'s sample exclude individuals aged 60 years or above. ${ }^{8}$

Table 4: Gini coefficients for annual and lifetime labor earnings

Sample simulated $\begin{gathered}\text { Sample of administrative } \\ \text { using estimated model }\end{gathered}$
social security records

Table 4 reports the results of our validation exercise. The first row of this table shows that the inequality of annual labor earnings implied by the estimated model closely matches that observed in the sample of administrative social security records (the Gini coefficients are equal to 0.319 and 0.336 , respectively). Of particular relevance for our later analysis, the second row of Table 4 shows that the inequality of lifetime labor earnings implied by the estimated model also closely matches that observed in the sample of administrative social security records

\footnotetext{
${ }^{8}$ Corneo (2015) reports further results from analysis of Bönke et al. (2015)'s sample. For further comparisons of the inequality of annual and lifetime earnings using administrative datasets of lifetime earnings see Kopczuk et al. (2010) and Guvenen et al. (2017) for the US, Björklund (1993) for Sweden, and Aaberge and Mogstad (2015) for Norway.
} 
(the Gini coefficients are equal to 0.208 and 0.212 , respectively). ${ }^{9}$ It follows that the estimated model replicates Bönke et al. (2015)'s finding that the inequality of lifetime labor earnings is around two-thirds of the inequality of annual labor earnings.

We also note that the inequality of annual labor earnings in the estimation sample is similar to the inequality of annual labor earnings in the simulated sample, which provides further support for the in-sample fit of the estimated model. The inequality of annual labor earnings in the estimation sample is also similar to the inequality of annual labor earnings in the sample of administrative social security records; this finding provides empirical support for the argument that the estimation sample and the sample of administrative social security records are comparable.

\section{Taxes, transfers \& the inequality of lifetime income}

We now turn to our first contribution, which is to use the estimated model to understand how taxes and transfers insure lifetime earnings risk and how they redistribute lifetime earnings. Before proceeding, we must consider the measurement of inequality. Our analysis requires us to work with an inequality measure that is additively decomposable into within- and betweenendowment components. The rules out using the Gini coefficient (see Cowell and Flachaire, 2015). Instead, our primary analysis focuses on the Theil index, which is a special case of the generalized entropy index. The Theil index for a sample of earnings (incomes) $\left\{y_{i}\right\}_{i=1}^{N}$ is given by:

$$
\frac{1}{N} \sum_{i=1}^{N} \frac{y_{i}}{\bar{y}} \ln \left(\frac{y_{i}}{\bar{y}}\right)
$$

where $\bar{y}$ denotes the sample mean of earnings (income).

We check the robustness of our results by reevaluating inequality using two alternative generalized entropy measures, namely the squared coefficient of variation and the mean logarithmic deviation. ${ }^{10}$ Compared to the Theil index, the squared coefficient of variation gives less weight to inequality at the bottom of the distribution while the mean logarithmic deviation gives more weight to inequality at the bottom of the distribution. Despite these differences, we show that our qualitative results hold irrespective of whether we measure inequality using the Theil index, the squared coefficient of variation or the mean logarithmic deviation.

\footnotetext{
${ }^{9}$ Although labor earnings were generally recorded accurately in the administrative data, measurement error is still present due to changes in recording techniques over the time and due to the censoring of recorded labor earnings at the level of the cap on labor earnings that are subject to a payroll deduction for pension benefits. For consistency, the calculations for the simulated sample reported in Table 4 use simulated wage observations that include measurement error. The Gini coefficients for the sample simulated using the estimated model but excluding measurement errors are 0.294 for annual labor earnings and 0.207 for lifetime labor earnings.

${ }^{10}$ The squared coefficient of variation and the mean logarithmic deviation are given by, respectively,

$$
\frac{\sum_{i=1}^{N}\left(y_{i}-\bar{y}\right)^{2} / N}{\bar{y}^{2}} \text { and } \frac{1}{N} \sum_{i=1}^{N} \ln \left(\frac{y_{i}}{\bar{y}}\right) .
$$
}




\subsection{Insurance and redistributive effects of taxes and transfers}

Using the Theil index, we have the following decomposition of the inequality of lifetime income:

$\underset{\text { Inequality of }}{\operatorname{lifetime} \text { income }}=\underset{\text { inequality of lifetime income }}{\text { Within-endowment }}+\begin{gathered}\text { Between-endowment } \\ \text { inequality of lifetime income }\end{gathered}$

The between-endowment inequality of lifetime income is a summary measure of the differences in average lifetime income between individuals with different endowments of education and productive ability. We define the redistributive effect of the tax-and-transfer system as the difference between the between-endowment inequality of lifetime earnings and the betweenendowment inequality of lifetime income. The within-endowment inequality of lifetime income reflects differences in lifetime income among individuals with the same endowment of education and productive ability. The within-endowment inequality of lifetime income is, therefore, a summary measure of the lifetime income consequences of risks that individuals cannot insure themselves against. We assess the insurance function of taxes and transfers by looking at how the tax-and-transfer system affects the within-endowment inequality of lifetime income. ${ }^{11}$

The separation of the insurance and redistributive effects of taxes and transfers is contingent on our assumptions about individuals' knowledge of the earnings process at the start of the life cycle. In particular, the within-endowment inequality of lifetime earnings can only be interpreted as lifetime income risk if shocks are truly unforeseen. Likewise, the effect of taxes and transfers on the between-endowment inequality of lifetime income can only be interpreted as redistribution if individuals are fully informed about the expected consequences of their endowment at the beginning of the life cycle.

We quantify each component of (11) using a sample of life-cycle income trajectories simulated from the estimated model. We repeat this exercise using earnings instead of income (the notes to Table 4 describe how we use the estimated model to simulate earnings and income trajectories). These calculations reveal the effect of taxes and transfers on the inequality of lifetime income or, equivalently, the share of lifetime earnings inequality that is offset by taxes and transfers. Throughout this exercise, we continue to focus on earnings and incomes of individuals younger than 60 years. In so doing, we abstract from the effects of old-age retirement and pensions on income inequality. ${ }^{12}$

Table 5 summarizes our findings. ${ }^{13}$ Interestingly, although taxes and transfers are based on annual earnings, the first column of Table 5 shows that the tax-and-transfer system is strongly

\footnotetext{
${ }^{11}$ Hoynes and Luttmer (2011) and Shaw (2014) adopt similar definitions of insurance and redistribution in the context of willingness to pay calculations.

${ }^{12}$ For a discussion about the distributional effects of pensions see, e.g., Conesa and Krueger (1999), Huggett and Parra (2010), Coronado et al. (2011), and Feldstein and Liebman (2002).

${ }^{13}$ Tables SWA.2 and SWA.3 in Appendix V show that the results reported in Table 5 continue to hold if inequality is measured using the squared coefficient of variation or the mean logarithmic deviation instead of the Theil index. Tables SWA.4 and SWA.5 in Appendix V shows that the results reported in Table 5 are robust to extending the estimated model to allow four or five productive ability types (instead of the three types that are included in the primary specification).
} 
progressive on a lifetime basis. In particular, our calculations show that taxes and transfers eliminate $50 \%$ of the inequality of lifetime income (see, e.g., Brewer et al., 2012, and Bengtsson et al., 2016, for similar findings). This is an important result because: i) the inequality of lifetime earnings is substantial (the inequality of lifetime earnings is around two-thirds as large as the inequality of annual earnings, see Table 4); and ii) inequalities in lifetime earnings represent cross-individual differences that people cannot mitigate by saving and borrowing. ${ }^{14}$

The second and third columns of Table 5 explore this result. We see that taxes and transfers combined offset $57 \%$ of the within-endowment inequality of lifetime earnings, i.e., around half of the inequality in lifetime earnings that arises from differences between the lifetime earnings of individuals with the same endowment is mitigated by taxes and transfers. Taxes and transfers together also offset a similar percentage-48\%-of the between-endowment inequality of lifetime earnings. In other words, close to half of the inequality in lifetime earnings that arises from education and productive ability is offset by taxes and transfers. Together these results show that the tax-and-transfer system provides substantial insurance against lifetime earnings risk and is strongly redistributive on a lifetime basis.

Table 5: Insurance and redistributive effects of the tax-and-transfer system

\begin{tabular}{|c|c|c|c|c|}
\hline & \multicolumn{3}{|c|}{$\begin{array}{l}\text { Inequality of lifetime earnings and lifetime income } \\
\qquad(100 \times \text { Theil index })\end{array}$} & \multirow{2}{*}{$\begin{array}{c}\text { Ratio of between- } \\
\text { endowment inequality } \\
\text { to total inequality }\end{array}$} \\
\hline & Total & Within-endowment & Between-endowment & \\
\hline $\begin{array}{l}\text { Earnings } \\
\text { (Labor earnings+ } \\
\text { interest income) }\end{array}$ & 7.38 & 1.27 & 6.11 & 0.83 \\
\hline $\begin{array}{l}\text { Income } \\
\qquad \text { (Earnings-taxes+transfers) }\end{array}$ & 3.69 & 0.54 & 3.15 & 0.85 \\
\hline $\begin{array}{l}\text { Share of earnings inequality offset } \\
\text { by the tax-and-transfer system }\end{array}$ & 0.50 & 0.57 & 0.48 & \\
\hline \multicolumn{5}{|c|}{$\begin{array}{l}\text { Notes: All calculations are based on a sample of } 10,000 \text { income trajectories of individuals aged } 20-59 \text { years } \\
\text { inclusive simulated from the estimated model (the notes to Table } 4 \text { describe how we use the estimated model } \\
\text { to simulate income trajectories). The column headed 'Total' reports the inequality of lifetime earnings } \\
\text { and lifetime income. The column headed 'Within-endowment' ('Between-endowment') reports the within- } \\
\text { endowment (between-endowment) inequality of lifetime earnings and lifetime income. Taxes include a pro- } \\
\text { gressive tax on annual labor earnings, a progressive tax on annual interest income, and social security taxes for } \\
\text { health and unemployment benefits (see Appendix II). Transfers include unemployment insurance, disability } \\
\text { benefits and social assistance (see Section 3.6). }\end{array}$} \\
\hline
\end{tabular}

We note that, although the tax-and-transfer system mitigates approximately equal shares of the within- and between-endowment inequality of lifetime earnings, in absolute terms the

\footnotetext{
${ }^{14}$ The model also implies that taxes and transfers reduce the Gini coefficient for annual income by 0.14 . This result aligns with previous studies, which have shown large mitigating effects of taxes and transfers on the inequality of annual income (see, e.g., Piketty and Saez, 2007, Heathcote et al., 2010, Fuchs-Schuendeln et al., 2010, Wang et al., 2012, DeBacker et al., 2013, and Bengtsson et al., 2016).
} 
redistributive effect of taxes and transfers is around four times larger than the insurance effect. This result reflects that $83 \%$ of the inequality in lifetime earnings is attributable to differences in individuals' endowments while only $17 \%$ of the inequality in lifetime earnings arises from the effects of shocks that vary among individuals with the same endowment (see the first row of Table 5). ${ }^{15}$

We now disaggregate the effects of the four programs that comprise the tax-and-transfer system (namely taxes, unemployment insurance, disability benefits and social assistance). This allows us to understand which programs are most effective at reducing the inequality of lifetime income and to identify the specific programs that account for the insurance the redistributive effects of the tax-and-transfer system. A complication arises here because the effect of each program depends on the order in which the programs are considered. We deal with this issue by using the permutation-based method of Shorrocks (2013) to derive the contribution of each program to income inequality in a way that is robust to ordering effects. According to this method, the order-robust effect of a program on income inequality is obtained by calculating the program's effect on income inequality for each of the twenty-four (i.e., four factorial) possible orders of the four programs and then averaging over the twenty-four possible program orders.

Table 6: Shares of lifetime earnings inequality offset by taxes and transfer programs

\begin{tabular}{lccc} 
& Total & $\begin{array}{c}\text { Within-endowment } \\
\text { (Insurance) }\end{array}$ & $\begin{array}{c}\text { Between-endowment } \\
\text { (Redistribution) }\end{array}$ \\
\cline { 2 - 4 } & & & 0.28 \\
Taxes & 0.24 & 0.07 & 0.03 \\
Unemployment insurance & 0.04 & 0.08 & -0.01 \\
Disability benefits & 0.00 & 0.07 & 0.19 \\
Social assistance & 0.22 & 0.36 & \\
\hline
\end{tabular}

Notes: All calculations are based on a sample of 10,000 income trajectories of individuals aged 20-59 years inclusive, simulated from the estimated model (the notes to Table 4 describe how we use the estimated model to simulate income trajectories). The column headed 'Total' reports the shares of the inequality of lifetime earnings that are offset by taxes, unemployment insurance, disability benefits and social assistance. The column headed 'Within-endowment' ('Betweenendowment') reports the shares of the within-endowment (between-endowment) inequality of lifetime earnings that are offset by taxes, unemployment insurance, disability benefits and social assistance. Shares are calculated from inequality as measured using the Theil index.

The first column of Table 6 shows that taxes reduce the inequality of lifetime income by $24 \%$ while the three transfer programs combined-unemployment insurance, disability benefits and social assistance-reduce the inequality of lifetime income by $26 \%$ (giving the aforementioned combined mitigating effect of the tax-and-transfer system on the inequality of lifetime income

\footnotetext{
${ }^{15}$ Our estimate of the share of the inequality of lifetime earnings that is explained by endowments is similar to that found by Keane and Wolpin (1997), who attribute $90 \%$ of the inequality of lifetime earnings to endowments. However, our estimate is higher than that reported by Huggett et al. (2011) (about 60\%) and Storesletten et al. (2004) (about 50\%). Huggett et al. (2011) discuss how the different findings are related to the specification of the endowments and the modeled sources of risk.
} 
of 50\%). Among the three transfer programs, social assistance is by far the most important program for reducing the inequality of lifetime income: social assistance offsets $22 \%$ of the inequality of lifetime earnings while unemployment insurance and disability benefits offset $4 \%$ and $0 \%$ of the inequality of lifetime earnings, respectively. ${ }^{16}$

The second and third columns of Table 6 report the effects of taxes and each of the three transfer programs on the within- and between-endowment inequality of lifetime income. These results, which we discuss in Sections 5.1.1-5.1.4, raise the following four questions about the insurance and redistributive effects of taxes and transfers. Why are taxes much more effective at redistributing lifetime income than insuring lifetime earnings risk? Why do disability benefits fail to redistribute lifetime earnings? What drives the redistributive effect of unemployment insurance? What makes social assistance the most important transfer program for insuring lifetime earnings risk and redistributing lifetime income? We address each of these questions in turn.

\subsubsection{Why are taxes much more effective at redistributing lifetime income than insuring lifetime earnings risk?}

Table 6 shows that taxes reduce the within-endowment inequality of lifetime income by only $7 \%$. Taxes thus provide relatively little insurance against lifetime earnings risk. In contrast, taxes reduce the between-endowment inequality of lifetime income by $28 \%$. Taxes are thus highly effective at redistributing lifetime income. Furthermore, since the majority of the inequality in lifetime earnings can be attributed to individuals' endowments (see the first row of Table 5), the difference between the insurance and redistributive effects of taxes is even larger in absolute terms: taxes reduce the Theil index $(\times 100)$ of the between- and within-endowment inequality of lifetime income by, respectively, 1.70 and 0.08 .

We first explain why taxes are largely ineffective at insuring lifetime earnings risk. We focus here on the annual labor earnings tax, which accounts for the majority share of all taxes (footnote 18 discusses the insurance and redistribuative effects of the social security tax and the tax on interest income). Starting from first principles, an annual labor earnings tax provides insurance to the extent that, within an endowment group, the share of lifetime earnings paid in tax increases with lifetime earnings. Since, within an endowment group, higher lifetime earnings reflect more years worked over the life cycle, a progressive annual labor earnings tax provides insurance only to the extent that annual labor earnings increase with experience. The modest insurance effect of the labor earnings tax that we find reflects that, because the estimated returns to experience are low (see Figure 2), labor earnings rise little with experience within

\footnotetext{
${ }^{16}$ Tables SWA.6 and SWA.7 in Appendix V show that social assistance becomes more important as the inequality measure gives more weight to the bottom of the income distribution. Despite this, we find that the pattern of effects reported in Table 6 continues to hold when inequality is measured using the squared coefficient of variation or the mean logarithmic deviation instead of the Theil index. Tables SWA.8 and SWA.9 shows that the introduction of additional productive ability types slightly decreases the importance of social assistance but, overall, the results reported in Table 6 are robust to extending the estimated model to include four or five productive ability types (instead of the three types that are allowed in the primary specification).
} 
an endowment group.

The limited insurance effect of the annual labor earnings tax represents a disadvantage of annual taxation relative to multi-year or lifetime taxation, as proposed by Vickrey (1939, 1947). In contrast to annual taxation, a progressive tax on lifetime labor earnings would directly target the within-endowment inequality of lifetime income and, therefore, would be effective at insuring lifetime earnings risk.

Next we explain why the annual labor earnings tax is highly effective at redistributing lifetime income between individuals with different endowments. Intuitively, a progressive annual labor earnings tax will be an effective redistributive device if the endowment-level average of labor earnings per year of work increases with the endowment-level average of lifetime earnings (or, equivalently, expected lifetime earnings). In this case, the progressivity of the annual labor earnings tax will ensure that individuals with high expected lifetime earnings pay a high average annual rate of tax during years of work and thus also pay a large share of their lifetime earnings in tax. Empirically, we find that the endowment-level average of labor earnings per year of work increases strongly with expected lifetime earnings. In fact, as shown in Figure 7(a), the crossendowment relationship between labor earnings per year of work and lifetime earnings is convex. Figure 7(b) shows that this relationship translates into an increasing and approximately linear cross-endowment relationship between the share of lifetime earnings paid in tax and average lifetime earnings, thus generating the large redistributive effect of the labor earnings tax. ${ }^{17,18}$

\footnotetext{
${ }^{17}$ The strength of the relationship between the endowment-level average of labor earnings per year of work and the endowment-level average of lifetime earnings depends on how the intensity of employment varies across endowments groups: the faster the rate of employment increases with the endowment-level average of lifetime earnings the lower the rate of increase of earnings per year of work with the endowment-level average lifetime earnings and, therefore, the lower the redistributive effect of the labor earnings tax. According to our results, the correlation between the endowment-level employment rate and endowment-level average of lifetime earnings is equal to 0.186 , which, while positive, is not sufficiently large to generate a negative cross-endowment relationship between labor earnings per year of work and lifetime earnings.

${ }^{18}$ Individuals also face a social security tax, which is a flat-rate tax on annual labor earnings below a cap. This tax offers no insurance against lifetime earnings risk and also fails to redistribute lifetime earnings: below the cap all individual pay the same share of their annual (and thus lifetime) labor earnings in tax, while the average tax rate on annual labor earnings actually falls when annual earnings exceed the cap. The tax on interest income offers some insurance against lifetime earnings risk: this is a progressive tax and, conditional on endowments, individuals with higher lifetime earnings have higher lifetime interest income. Likewise, due to its progressivity and the positive cross-endowment relationship between interest income and lifetime earnings (the correlation is equal to 0.250), the tax on interest income redistributes lifetime earnings. However, because the tax on interest income accounts a minor share of all taxes paid, the insurance and redistributive effects of this tax are negligible.
} 
Figure 7: Redistributive effect of the annual labor earnings tax

(a)

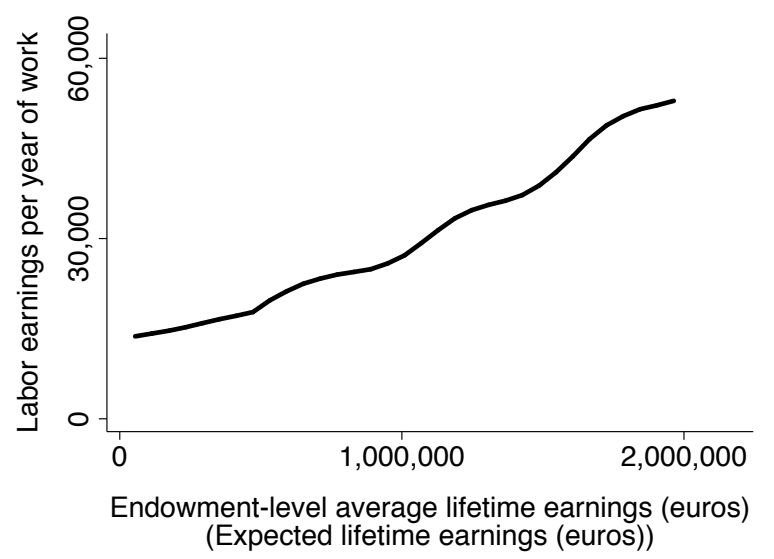

(b)

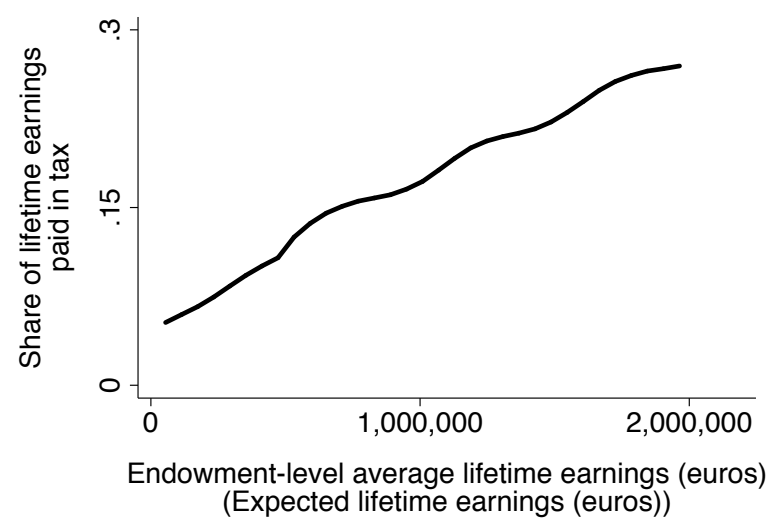

Notes: Smoothed Nadaraya-Watson kernel regressions estimated using the simulated sample described in the notes to Table 5. Dependent variables are endowment-level averages.

\subsubsection{Why do disability benefits fail to redistribute lifetime earnings?}

Table 6 shows that disability benefits do not redistribute lifetime earnings between groups of individuals with different endowments of education and productive ability. Quantitatively, disability benefits increase the between-endowment inequality of lifetime income by one percentage point, which is a small effect compared to the $48 \%$ reduction in the between-endowment inequality of lifetime income that is achieved by the composite tax-and-transfer system.

At first sight, the absence of a redistributive effect for disability benefits is counterintuitive: given that education increases both expected lifetime earnings and the likelihood of being in good health (and thus decreases the likelihood of being eligible for disability benefits), we expect disability benefits to reduce the inequality in lifetime income between individuals with high education (and therefore high expected lifetime earnings) and individuals with low education (and therefore low expected lifetime earnings). The reason that disability benefits in fact fail to redistribute lifetime earnings is based on the pattern of disability benefit take up. Specifically, Figure 8 shows that, while the rate of eligibility for disability benefits generally decreases with expected lifetime earnings, the rate of disability benefit receipt increases with expected lifetime earnings over most of the range of expected lifetime earnings. This pattern of selection into disability benefit receipt is driven by the interaction between disability benefits and social assistance. Recall, value of the disability benefits increases with lifetime earnings while social assistance ensure minimum annual income that does not depend on past earnings. Thus, as expected lifetime earnings increase so does the fraction of individuals who prefer disability benefits to social assistance. 
Figure 8: Redistributive effect of disability benefits

(a) Eligibility

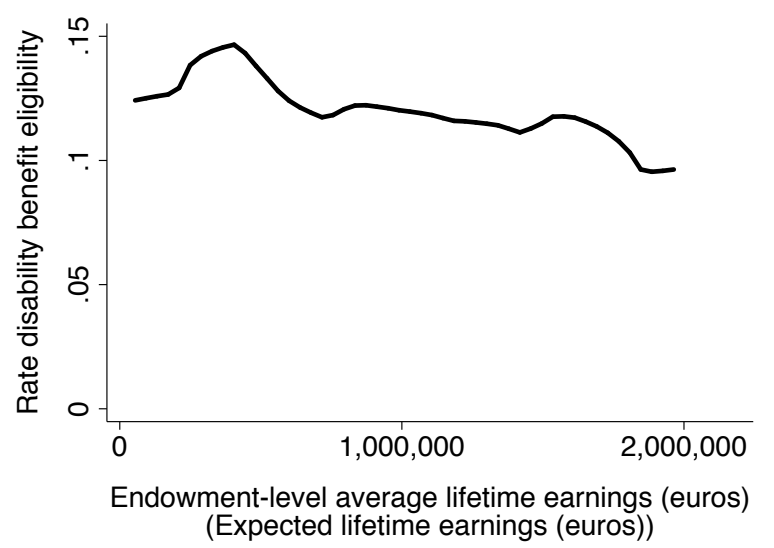

(b) Take-up

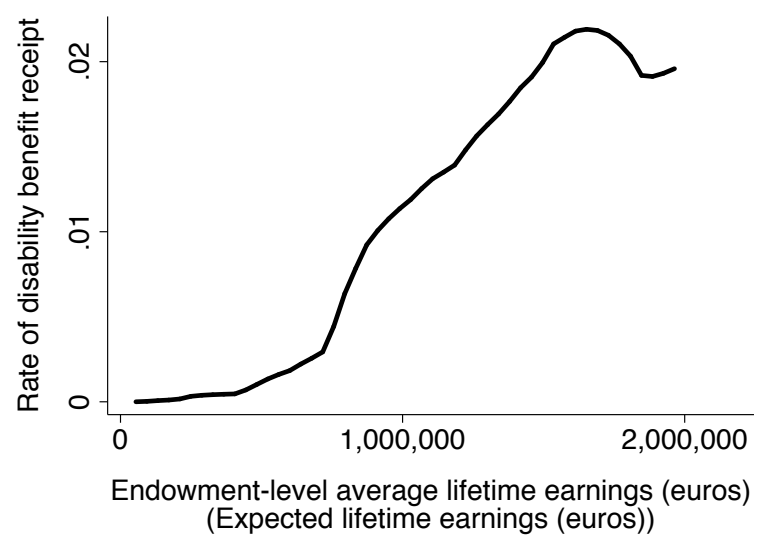

Notes: Smoothed Nadaraya-Watson kernel regressions estimated using the simulated sample described in the notes to Table 5. The dependent variable in panel (a) is the endowment-level average of an individual-year-level indicator of eligibility for disability benefits (an individual is eligible for disability benefits in a given year if he is in bad health in that year). The dependent variable in panel (b) is the endowment-level average of an individual-year-level indicator of disability benefit receipt (an individual is defined to receive disability benefits in a given year if he has non-zero disability benefit income in that year).

\subsubsection{What drives the redistributive effect of unemployment insurance?}

Unemployment insurance is designed to provide short-term insurance against job loss, and is not generally considered to be a redistributive program. However, we find that unemployment insurance is mildly redistributive. Specifically, Table 6 shows that unemployment insurance eliminates three percent of the between-endowment inequality of lifetime income. This result is driven by the decrease in the risk of a job separation with education and the increase in health status with education, which further reduces the job separation risk (see Table 2). This pattern of employment risk leads unemployment insurance receipt to be concentrated among individuals with low expected lifetime earnings. In particular, in our simulated sample individuals with expected lifetime earnings below 500,000 euros receive unemployment insurance for an average of 3.1 years between age 20 years and age 60 years, while individuals with expected lifetime earnings above 1,500,000 euros receive unemployment insurance for an average of 0.6 years during the same time period.

\subsubsection{What makes social assistance the most important transfer program for in- surance and redistribution?}

Among the three transfer programs, social assistance has by far the largest effect on the inequality of lifetime income: Table 6 shows that social assistance eliminates $22 \%$ of the inequality of lifetime income, while unemployment insurance and disability benefits eliminate, respectively, $4 \%$ and $0 \%$ of the inequality of lifetime income. Table 6 further shows that social assistance is important for insuring lifetime earnings risk and redistributing lifetime income. In particu- 
lar, social assistance offsets $36 \%$ of the within-endowment inequality of lifetime earnings and mitigates $19 \%$ of the between-endowment inequality of lifetime earnings. The insurance and redistributive effects of social assistance comfortably exceed those of unemployment insurance and disability benefits.

To understand why social assistance has large insurance and redistributive effects we must consider the rules that are used to calculate social assistance. As explained in Section 2.2, social assistance makes up the difference between an individual's income from all other sources and a minimum income guarantee. The minimum income guarantee decreases with wealth and is zero for individuals who are sufficiently wealthy. We explore the effects of social assistance by separating the income-based determinants of social assistance from the effect of the wealthbased adjustment to the minimum income guarantee. In particular, we learn about the incomebased determinants of social assistance by studying the 'social assistance income gap', defined as the difference between the non-wealth-adjusted minimum income guarantee and individual's annual income before social assistance. We parse out the effect of the wealth-based social assistance rules by studying how often the wealth-based adjustment to the minimum income guarantee reduces the social assistance received by income-eligible individuals to zero, i.e., we study the fraction of income-eligible individuals who fail the social assistance wealth test.

We first consider the insurance effect of social assistance. We focus on the same six endowment groups as considered in Figure 2. Figure 9(a) shows that within each endowment group the social assistance income gap decreases rapidly with lifetime earnings, indicating that the income-based social assistance rules make social assistance an effective insurance device. This occurs because the income-based rules for social assistance focus the benefit on individuals with low annual income from other sources and, among individuals with the same endowment, those with low lifetime earnings experience many years with low income.

Figure 9(b) shows that within each endowment group the fraction of individuals who fail the wealth test generally decreases with lifetime earnings. This pattern arises because, conditional on endowments, individuals with relatively high lifetime earnings typically have annual incomes (excluding social assistance) that are below the non-wealth adjusted minimum income guarantee only when they are young. These young individuals generally have low wealth and thus actually receive social assistance. Meanwhile, within an endowment group, individuals with relatively low lifetime earnings typically have annual incomes (excluding social assistance) that are below the non-wealth adjusted minimum income guarantee at several difference times during the life cycle, including at older ages when they have accumulated sufficient wealth to make themselves ineligible for social assistance. Quantitatively, we find that individuals in the same endowment group are, on average, 5.8 percentage points less likely to receive social assistance at age 59 years than at age 20 years. This pattern shows that the wealth-based adjustment reduces the insurance effect of social assistance. Further calculations show that the effect of the wealth test on the insurance effect of social assistance is substantial. Specifically, eliminating the wealth adjustment increases the share of within-endowment inequality in lifetime earnings that is offset 
Figure 9: Insurance effect of social assistance

(a) Income effect

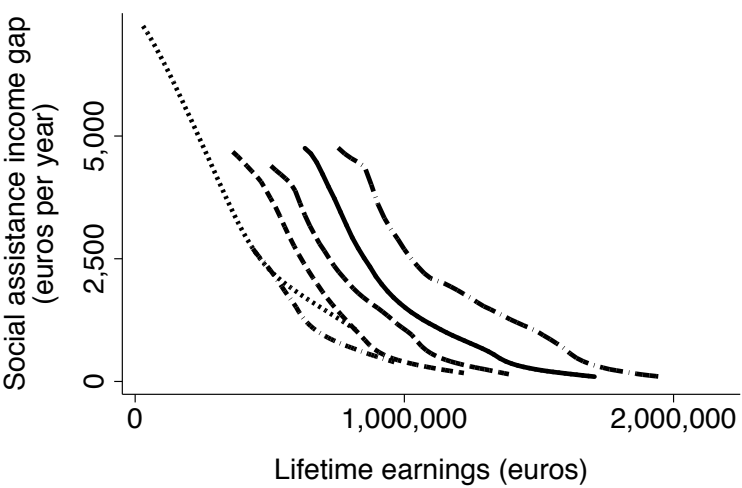

(b) Wealth effect

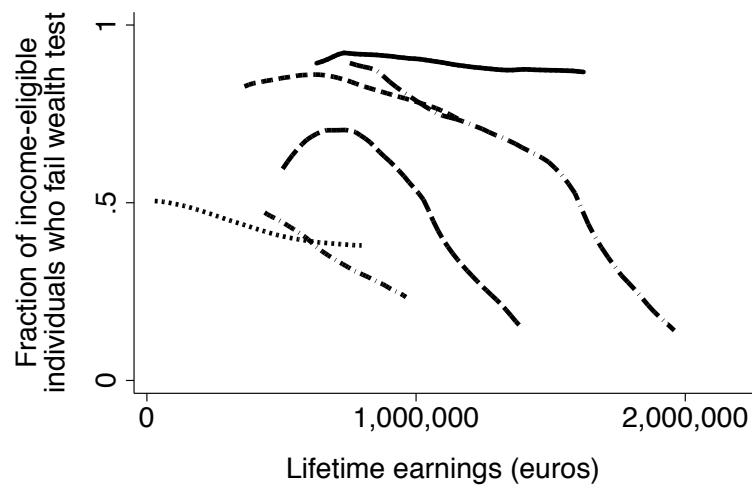

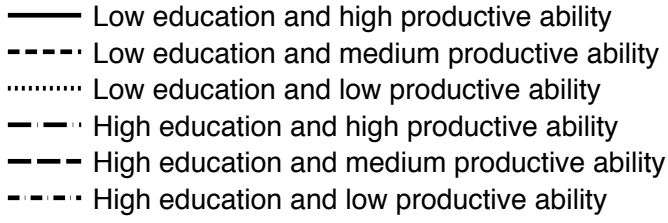

Notes: Smoothed Nadaraya-Watson kernel regressions estimated using the simulated sample described in the notes to Table 5. The dependent variable in the regressions illustrated in panel (a) is an individual-year-level variable that is equal to the difference between the non-wealth-adjusted annual minimum income guarantee and an individual's annual income before social assistance (this variable is censored at zero and thus is equal to zero if the individual's annual income before social assistance is greater than the non-wealth-adjusted annual minimum income guarantee). The dependent variable in the regressions illustrated in panel (b) is an individual-year-level indicator for an individual's annual social assistance income being reduced to zero by the wealth-based adjustment to the annual minimum income guarantee (these regression are estimated using only individual-year observations where the individual was eligible for social assistance on the basis of income). 'Low education' refers to eleven years of education and 'high education' refers to fourteen years of education.

by social assistance from $36 \%$ (see Table 6 ) to $49 \%$.

We now turn to the redistributive effect of social assistance. We again separate the effects of the income-based and wealth-based determinants of social assistance. Figure 10(a) shows that the social assistance income gap is modest, only around 200 euros per person per year, for individuals with expected lifetime earnings above 1,000,000 euros. However, the social assistance income gap increases sharply as expected lifetime earnings decrease below this level, and reaches over 5,000 euros per person per year for individuals with the lowest level of expected lifetime earnings. This pattern implies that the income-based rules for social assistance are strongly redistributive. Intuitively, social assistance targets the incomes of individuals with low expected lifetime incomes because the income-based rules for social assistance focus the benefit on individuals with low annual income (before social assistance) and individuals with low expected lifetime earnings tend to experience many years of low income during their lives.

Figure 10(b) shows a hump-shaped relationship between ineligibility for social assistance on the basis of wealth and expected lifetime earnings: individuals with expected lifetime earnings below 750,000 euros or above 1,700,000 euros are most likely to remain eligible for social 
Figure 10: Redistributive effect of social assistance

(a) Income effect

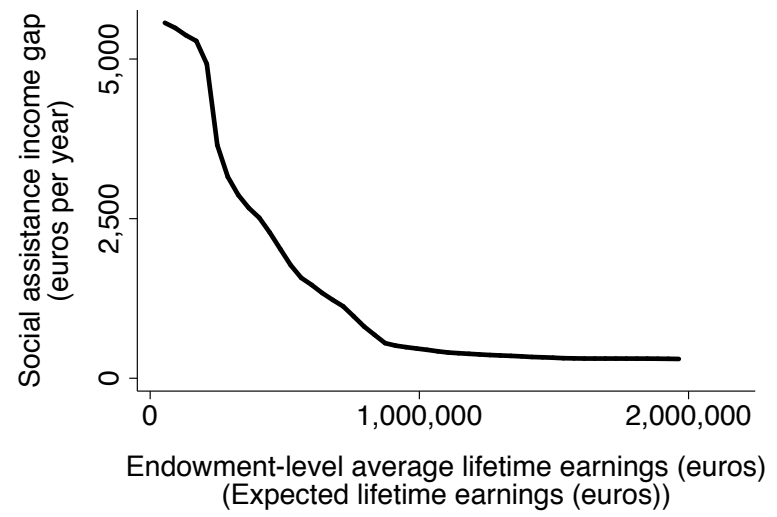

(b) Wealth effect

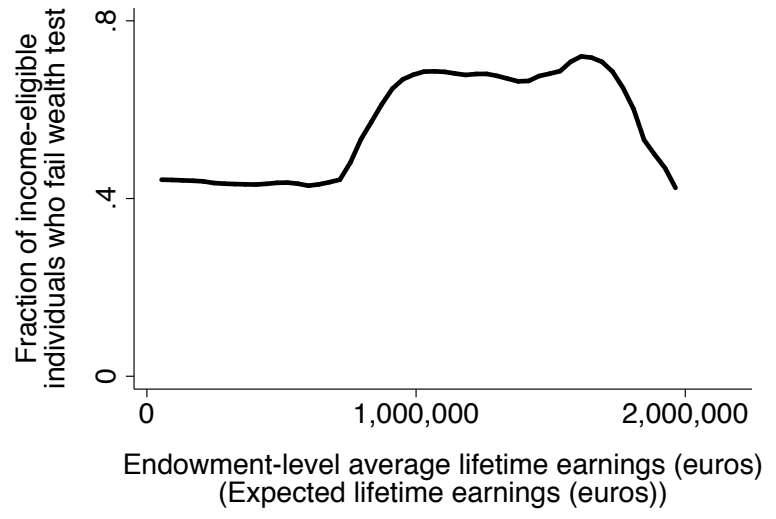

Notes: Smoothed Nadaraya-Watson kernel regressions estimated using the simulated sample described in the notes to Table 5. Dependent variables are endowment-level averages of the individual-year-level variables defined in the notes to Figure 9.

assistance once benefits are adjusted for wealth, while individuals with intermediate levels of expected lifetime earnings are most likely to fail the wealth test. Intuitively, individuals with expected lifetime earnings below 750,000 euros typically have low wealth at all ages and thus the wealth-based adjustment is unlikely to reduce the value of their social assistance to zero. Meanwhile, those with expected lifetime earnings above 1,700,000 euros generally have annual incomes that are below the non-wealth-adjusted minimum income guarantee only when they first enter the labor market, and at this point their wealth is typically low enough to allow them to actually receive social assistance. More precisely, while the average age of all social assistance recipients is 36.1 years, social assistance recipients with expected lifetime earnings above $1,700,000$ euros have an average age of only 29.9 years.

Given that the effect of the wealth-based adjustment to social assistance varies non-monotonically with expected lifetime earnings, it is unclear whether the wealth-based adjustment to social assistance enhances or diminishes the redistributive effect of social assistance. We look into this question by calculating how the share of the between-endowment inequality in lifetime earnings that is offset by social assistance changes when the wealth-adjustment is eliminated. We find that eliminating the wealth adjustment increases the share of the between-endowment inequality in lifetime earnings that is offset by social assistance from $19 \%$ (see Table 6) to 21\%. The wealth-based adjustment thus reduces the redistributive effect of social assistance (although, comparing to our earlier calculations, we find that the wealth-based adjustment to social assistance is more detrimental to insurance than to redistribution).

While the annual wealth test reduces the redistributive and insurance effects of social assistance, the wealth test also reduces the financial cost of providing social assistance. Switching to a lifetime wealth test could improve the insurance and redistributive effects of social assistance without additional costs. In particular, instead of basing the wealth test on annual wealth, a lifetime wealth test would force individuals with high wealth later in life to repay any social 
assistance received when younger.

\section{Insurance of lifetime employment and health risks}

In the final section of the paper, we focus on the inequality in lifetime earnings that is generated by specific risks to lifetime earnings. In particular, we study how changes in employment and health risks affect the inequality of lifetime earnings, and we explore how taxes and transfer programs insure the extra inequality in lifetime earnings that arises from increases in employment and health risks. This analysis leverages the estimated life-cycle model in two important respects. First, we use the model to learn how specific changes in employment and health risks affect the inequality of lifetime earnings. This contrasts with the earlier decomposition-based analysis, which pooled together all sources of lifetime earnings risk. Second, because the model captures how individuals optimally adjust labor supply and savings behavior in response to changes in employment and health risks, we can use the model to study how taxes and transfer programs insure risks while accounting for the partially substitutable self-insurance that individuals obtain by adjusting their behavior in response to risks.

We consider four employment and health risk environments: the baseline environment and three counterfactual risk environments in which individuals face an increased risk of adverse employment or health events. In the baseline environment, health shocks, job offers, and job separations occur at the rates implied by the estimated life-cycle model (see Figure 3 and Table 2). In the first counterfactual environment, employed individuals face an increased risk of experiencing a job separation, in the second counterfactual environment, nonemployed individuals face a decreased risk of receiving a job offer, and in the third counterfactual environment, individuals face an increased risk of bad health shocks. In all three counterfactual environments, we calibrate proportional adjustments in the risk probabilities to obtain a one percentage point reduction in the employment rate from the baseline rate. ${ }^{19}$ The three counterfactual environments, therefore, have different employment and health risks but the same employment rate.

Table 7 summarizes individuals' employment behavior and health status in the four risk environments. The employment rate is $86 \%$ in the baseline environment and, by construction, $85 \%$ in the counterfactual environments. The higher frequency of job separations increases the average number of nonemployment spells per person from 1.03 to 1.12 but has hardly any effect on the average number of nonemployment spell duration. In contrast, the decrease in the rate of job offers increases the average nonemployment spell duration from 3.62 years to 4.85 years. At the same time, the average number of nonemployment spells per person decreases to 0.81 , reflecting compositional difference in the pool of employed individuals. The increased risk of bad health shocks increases the rate of bad health from $11 \%$ to $15 \%$ and increases the average number of bad health spells per person from 0.76 to 1.00 .

\footnotetext{
${ }^{19}$ The calibrated risk adjustments are $14.0 \%$ in the first counterfactual environment, $34.3 \%$ in the second counterfactual environment, and $39.9 \%$ in the third counterfactual environment.
} 


\begin{tabular}{|c|c|c|c|c|}
\hline & Baseline & $\begin{array}{c}\text { Increased job } \\
\text { separation risk }\end{array}$ & $\begin{array}{c}\text { Decreased job } \\
\text { offer rate }\end{array}$ & $\begin{array}{l}\text { Increased risk of } \\
\text { bad health shocks }\end{array}$ \\
\hline Employment rate & 0.86 & 0.85 & 0.85 & 0.85 \\
\hline Average nonemployment spells per person & 1.03 & 1.12 & 0.81 & 1.03 \\
\hline Average nonemployment spell duration (years) & 3.61 & 3.63 & 4.85 & 3.83 \\
\hline Rate of bad health & 0.11 & 0.11 & 0.11 & 0.15 \\
\hline Average bad health spells per person & 0.76 & 0.76 & 0.76 & 1.00 \\
\hline Average bad health spell duration (years) & 6.06 & 6.06 & 6.06 & 6.15 \\
\hline
\end{tabular}

Notes: Calculations for all three risk environments are based on samples of 10,000 life-cycle trajectories of individuals aged 20-59 years inclusive, simulated from the estimated model (the notes to Table 4 describe how we use the estimated model to simulate employment trajectories). Results for the baseline environment were calculated using the estimated parameter values. Results for the environment with increased job separation risk were obtained by proportionally increasing the estimated job separation probabilities to reduce the employment rate by one percentage point from the baseline rate. Results for the environment with the decreased job offer rate were obtained by proportionally decreasing the estimated job offer probabilities to reduce the employment rate by one percentage point from the baseline rate. Results for the environment with the increased risk of bad health shocks were obtained by proportionally increasing the estimated probability of a transition from good to bad health status to reduce the employment rate by one percentage point from the baseline rate.

The first row of Table 8 shows that the increase in job separation risk, the decrease in the job offer rate, and the increase in the risk of bad health shocks lead to sizable increases in the within-endowment inequality of lifetime earnings. Relative to the baseline environment, the within-endowment inequality of lifetime earnings increases by around $10 \%$ in response to the increase in job separation risk and increases by over $40 \%$ in response to the decrease in the job offer rate. The increase in the risk of bad health shocks, meanwhile, increases the within-endowment inequality of lifetime earnings by almost $20 \%$. The relatively large increase in inequality associated with the decrease in the job offer rate reflects that this risk increase extends nonemployment durations, thereby depressing the lifetime earnings of individuals at the bottom of the distribution of lifetime earnings. 


\begin{tabular}{|c|c|c|c|c|}
\hline & \multirow[b]{2}{*}{$\begin{array}{l}\text { Within-endowment } \\
\text { inequality in baseline }\end{array}$} & \multicolumn{3}{|c|}{$\Delta$ Within-endowment inequality } \\
\hline & & $\begin{array}{l}\text { Increased job } \\
\text { separation risk }\end{array}$ & $\begin{array}{l}\text { Decreased job } \\
\text { offer rate }\end{array}$ & $\begin{array}{l}\text { Increased risk of } \\
\text { bad health shocks }\end{array}$ \\
\hline $\begin{array}{l}\text { Lifetime earnings } \\
\text { (Labor earnings+ } \\
\text { interest income) }\end{array}$ & 1.27 & 0.12 & 0.56 & 0.22 \\
\hline $\begin{array}{l}\text { Lifetime income } \\
\qquad(\text { Earnings }- \text { taxes +transfers })\end{array}$ & 0.54 & 0.05 & 0.22 & 0.08 \\
\hline $\begin{array}{l}\text { Share of extra within- } \\
\text { endowment inequality offset } \\
\text { by the tax-and-transfer } \\
\text { system }\end{array}$ & & 0.60 & 0.61 & 0.63 \\
\hline
\end{tabular}

Notes: Inequality is measured using $(100 \times)$ the Theil index. ' $\Delta$ Within-endowment inequality' is the increase in within-endowment inequality from the baseline environment. Also see notes to Table 7 .

Table 8 also shows that around $60 \%$ of the increase in lifetime earnings risk that arises from additional employment risk is mitigated by the tax-and-transfer system while the remaining $40 \%$ of the extra earnings risk passes through into inequality in lifetime income. The tax-and-transfer system therefore insures the majority of the additional earnings risk associated with increases in employment risk. The tax-and-transfer system provides a similar level of insurance against health shocks: $63 \%$ of the extra within-endowment inequality of lifetime earnings associated with an increase in the risk of bad health shocks is mitigated by the tax-and-transfer system. ${ }^{20}$

Table 9 explores the insurance effect of the tax-and-transfer system in more detail by separating out the effects of taxes, unemployment insurance, disability benefits, and social assistance. We find that transfers rather than taxes are primarily responsible for insurance that the tax-and-transfer system provides against employment and health shocks: irrespective of the source of the increase in inequality, taxes mitigate only $8 \%$ of the increase in the withinendowment inequality of lifetime earnings. Meanwhile, transfer programs offset around half of the extra within-endowment inequality in lifetime earnings. However, the relative importance of each of the three transfer programs-unemployment insurance, disability benefits and social assistance-depends on the source of the increase in the within-endowment inequality of lifetime

\footnotetext{
${ }^{20}$ Tables SWA.10 and SWA.11 in Appendix V explore the robustness of the results in Table 8 to measuring inequality using the squared coefficient of variation and the mean logarithmic deviation instead of the Theil index. Irrespective of the measure of inequality, the tax-and-transfer system offers essentially equal amounts of insurance against the two different employment risks. The amount of insurance increases as we move to inequality measures that give more weight to the bottom of the income distribution, reflecting that the tax-andtransfer system is relatively effective at mitigating increases in the inequality of lifetime earnings among the lifetime poor. Tables SWA.12 and SWA.13 in Appendix V show that the results reported in Table 8 are robust to extending the estimated model to allow four or five productive ability types (instead of the three types that are included in the primary specification).
} 
Table 9: Shares of additional within-endowment lifetime earnings inequality offset by taxes and transfer programs

\begin{tabular}{lccc}
\hline \hline & $\begin{array}{c}\text { Increased job } \\
\text { separation risk }\end{array}$ & $\begin{array}{c}\text { Decreased job } \\
\text { offer rate }\end{array}$ & $\begin{array}{c}\text { Increased risk of } \\
\text { bad health shocks }\end{array}$ \\
\cline { 2 - 4 } Taxes & 0.08 & 0.08 & 0.08 \\
Unemployment insurance & 0.08 & 0.03 & 0.05 \\
Disability benefits & 0.07 & 0.04 & 0.14 \\
Social assistance & 0.36 & 0.47 & 0.37 \\
\end{tabular}

Notes: Shares are calculated from inequality as measured using the Theil index. Also see notes to Table 7 .

earnings.

In more detail, unemployment insurance mitigates $8 \%$ of the increase in the within-endowment inequality of lifetime earnings that arises from an increase in job separation risk but offsets only $3 \%$ of the extra within-endowment inequality that arises from a decrease in the job offer rate. This pattern reflects that, since unemployment insurance provides income replacement only during the first period of a nonemployment spell, this transfer program is well placed to mitigate the effects of job separation risk, which affects the frequency but not the duration of nonemployment. Since unemployment insurance does not provide long-term income replacement, it is less effective at mitigating the effects of lifetime earnings risk that is driven by a decrease in the job offer rate, which increases the average duration of nonemployment spells.

Disability benefits mitigate $14 \%$ of the increase in the within-endowment inequality of lifetime earnings that arises from an increase in the risk of bad health shocks. Although bad health status makes an individual eligible for disability benefits, the amount of insurance that disability benefits provide is limited because disability benefits only partially replace lost earnings and preclude future employment. Nonetheless, disability benefits are more effective at insuring health risk than employment risk: disability benefits mitigate $4-7 \%$ of the within-endowment increase in inequality that arises from increased employment risk (compared to $14 \%$ for health risk). This pattern reflects that some bad-health individuals who experience a job separation or who are nonemployed and without a job offer choose to claim disability benefits. We note that, because individuals with long periods of nonemployment in their work history are not entitled to generous disability benefits, disability benefits are less effective at insuring earnings risk that arises from a decrease in the job offer rate than they are at insuring earnings risk that is generated by the increase in job separation risk.

Social assistance is the most effective program for providing insurance against all types of risks to lifetime earnings. However, social assistance is particularly effective at providing insurance against earnings risk that arises from a decrease in the job offer rate. This reflects that social assistance is a permanent transfer and thus is effective at mitigating the lifetime 
income consequences of the increase in nonemployment durations that arises from a decrease in the job offer rate. ${ }^{21}$

\section{Conclusion}

The tax-and-transfer system has the potential to redistribute lifetime earnings between individuals with different skill endowments, thus counteracting the inequality in lifetime earnings that is due to individual differences that originate early in life. The tax-and-transfer system may also mitigate differences in lifetime earnings that arise from unpredictable events that individuals experience during their lifetimes, such as job loss, difficulty in finding employment, or changes in health status. That is, taxes and transfers may provide individuals with insurance against lifetime earnings risk. In this paper, we have shown how the tax-and-transfer system insures lifetime earnings risk and how it redistributes lifetime earnings between individuals with different skill endowments.

Our results on redistribution show that the tax-and-transfer system absorbs around half of the inequality in lifetime earnings that can be attributed to differences in skill endowments. This finding in relevant to discussions of the inequality-increasing effects of skill-biased technological change (e.g., Bekman et al., 1998, Autor et al., 2003). In particular, to the degree that skillbiased technological change increases earnings inequality by raising the returns to endowments, our results suggest that only half of the extra inequality in lifetime earnings associated with skill-biased technological change will pass through into inequality in lifetime income. We also find that the tax-and-transfer system offers considerable insurance against lifetime earnings risk. In particular, the tax-and-transfer system insures around $60 \%$ of the inequality in lifetime earnings that can be attributed to employment and health shocks. The insurance function of the tax-and-transfer system primarily operates through social assistance.

Our findings suggest two possible reforms to the tax-and-transfer system that may improve its lifetime properties. First, the lifetime insurance effect of the tax-and-transfer system may be increased by switching to a system of lifetime taxation. While progressive annual taxation offers limited insurances against lifetime earnings risk, a progressive tax on lifetime earnings, as discussed by Vickrey $(1939,1947)$, would directly target unexpected differences in lifetime earnings and, therefore, would provide individuals with more insurance against lifetime earnings risk. Second, the lifetime insurance and redistributive effects of social assistance may be increased, without additional financial costs, by replacing the annual wealth test with a lifetime wealth test that requires individuals with high wealth later in life to repay any social assistance received when younger.

\footnotetext{
${ }^{21}$ Tables SWA.14 and SWA.15 in Appendix V show that the results in Table 9 to are qualitatively robust to measuring inequality using the squared coefficient of variation and the mean logarithmic deviation instead of the Theil index. Tables SWA.16 and SWA.17 in Appendix V shows that the results reported in Table 9 are robust to extending the estimated model to allow four or five productive ability types (instead of the three types that are included in the primary specification).
} 


\section{References}

Aaberge, R. and Mogstad, M. (2015). Inequality in current and lifetime income. Social Choice and Welfare, 44(2):217-230

Arcidiacono, P. and Jones, J.B. (2003). Finite mixture distributions, sequential likelihood and the EM algorithm. Econometrica, 71(3):933-946

Autor, D.H., Levy, F., and Murnane, R.J. (2003). The skill content of recent technological change: An empirical exploration. Quarterly Journal of Economics, 118(4):1279-1333

Bartels, C. (2012). Redistribution and insurance in the German welfare state. Schmollers Jahrbuch, 132(2):265-295

Bekman, E., Bound, J., and Machin, S. (1998). Implications of skill-biased technological change: International evidence. Quarterly Journal of Economics, 113(4):1245-1279

Bengtsson, N., Holmlund, B., and Waldenström, D. (2016). Lifetime versus annual tax-andtransfer progressivity: Sweden, 1968-2009. Scandinavian Journal of Economics, 118(4):619-645

Berndt, E., Hall, B., Hall, R., and Hausman, J. (1974). Estimation and inference in nonlinear statistical models. Annals of Economic and Social Measurement, 3(4):653-665

Bhuller, M., Mogstad, M., and Salvanes, K.G. (2017). Life-cycle earnings, education premiums, and internal rates of return. Journal of Labor Economics, 35(4):993-1030

Björklund, A. (1993). A comparison between actual distributions of annual and lifetime income: Sweden 1951-89. Review of Income and Wealth, 39(4):377-386

Björklund, A. and Palme, M. (2002). Income redistribution within the life cycle versus between individuals: Empirical evidence using swedish panel data. In The Economics of Rising Inequalities, 205. Oxford University Press, Oxford, United Kingdom

Blundell, R., Dias, M., Meghir, C., and Shaw, J. (2016). Female labour supply, human capital and welfare reform. Econometrica, 84(5):1705-1753

Blundell, R., Graber, M., and Mogstad, M. (2015 July). Labor income dynamics and the insurance from taxes, transfers, and the family. Journal of Public Economics, 127:58-73

Bonhomme, S. and Robin, J.M. (2009). Assessing the equalizing force of mobility using short panels: France, 1990-2000. Review of Economic Studies, 76(1):63-92

Bönke, T., Corneo, G., and Lüthen, H. (2015). Lifetime earnings inequality in Germany. Journal of Labor Economics, 33(1):171-208

Bovenberg, A.L., Hansen, M.I., and Sørensen, P.B. (2008). Individual savings accounts for social insurance: Rationale and alternative designs. International Tax and Public Finance, 15(1):67-86

Bowlus, A.J. and Robin, J.M. (2004). Twenty years of rising inequality in U.S. lifetime labor income values. Review of Economic Studies, 71(3):709-743

Bowlus, A.J. and Robin, J.M. (2012). An international comparison of lifetime labor income values and inequality. Journal of the European Economic Association, 10(6):1236-1262

Brewer, M., Dias, M.C., and Shaw, J. (2012). Lifetime inequality and redistribution. Tech- 
nical report, IFS Working Papers 12/23

Conesa, J.C. and Krueger, D. (1999). Social Security reform with heterogeneous agents. Review of Economic Dynamics, 2(4):757-795

Corneo, G. (2015). Income inequality from a lifetime perspective. Empirica, 42(2):225-239

Coronado, J.L., Fullerton, D., and Glass, T. (2011). The progressivity of Social Security. BE Journal of Economic Analysis \& Policy, 11(1)

Cowell, F.A. and Flachaire, E. (2015). Statistical methods for distributional analysis. In Handbook of Income Distribution, chapter 6, 359-465. Elsevier

Cramer, C. (2003). Does inequality cause conflict? Journal of International Development, 15(4):397-412

DeBacker, J., Heim, B., Panousi, V., Ramnath, S., and Vidangos, I. (2013 Spring). Rising inequality: Transitory or persistent? New evidence from a panel of US tax returns. Brookings Papers on Economic Activity, 67-142

Eckstein, Z. and Wolpin, K. (1989). Dynamic labour force participation of married women and endogenous wage growth. Review of Economic Studies, 56(3):375-390

Falkingham, J. and Harding, A. (1996). Poverty alleviation vs social insurance systems: A comparison of lifetime redistribution. Contributions to Economic Analysis, 232:233-266

Fan, J. and Gijbels, I. (1996). Monographs on Statistics and Applied Probability 66: Local Polynomial Modelling and its Applications. Chapman \& Hall / CRC Press

Feldstein, M. and Liebman, J. (2002). Social Security. In A.J. Auerbach and M. Feldstein (editors), Handbook of Public Economics, volume V, 2246-2324

Flinn, C. (2002). Labour market structure and inequality: A comparison of Italy and the U.S. Review of Economic Studies, 69(3):611-645

Fuchs-Schuendeln, N., Krueger, D., and Sommer, M. (2010). Inequality trends for Germany in the last two decades: A tale of two countries. Review of Economic Dynamics, 13(1):103-132

Guvenen, F., Kaplan, G., Song, J., and Weidner, J. (2017 April). Lifetime incomes in the United States over six decades. NBER Working Papers 23371

Haan, P. and Prowse, V.L. (2015 April). Optimal social assistance and unemployment insurance in a life-cycle model of family labor supply and savings. IZA Discussion Papers 8980, Institute for the Study of Labor (IZA)

Heathcote, J., Perri, F., and Violante, G.L. (2010). Unequal we stand: An empirical analysis of economic inequality in the United States, 1967-2006. Review of Economic Dynamics, 13(1):15-51

Hoynes, H.W. and Luttmer, E.F. (2011). The insurance value of state tax-and-transfer programs. Journal of Public Economics, 95(11):1466-1484

Huggett, M. and Parra, J.C. (2010). How well does the US social insurance system provide social insurance? Journal of Political Economy, 118(1):76-112

Huggett, M., Ventura, G., and Yaron, A. (2011). Sources of lifetime inequality. American Economic Review, 101(7):2923-2954 
Imai, S. and Keane, M.P. (2004). Intertemporal labor supply and human capital accumulation. International Economic Review, 45(2):601-641

Keane, M.P. and Wolpin, K.I. (1994). The solution and estimation of discrete choice dynamic programming models by simulation and interpolation: Monte Carlo evidence. Review of Economics and Statistics, 76(4):648-672

Keane, M.P. and Wolpin, K.I. (1997 June). The career decisions of young men. Journal of Political Economy, 105(3):473-522

Kelly, M. (2000). Inequality and crime. Review of Economics and Statistics, 82(4):530-539

Kopczuk, W., Saez, E., and Song, J. (2010). Earnings inequality and mobility in the United States: Evidence from Social Security data since 1937. Quarterly Journal of Economics, 125(1):91-128

Levell, P., Roantree, B., and Shaw, J. (2017 Aug). Mobility and the lifetime distributional impact of tax and transfer reforms. Technical report, IFS Working Paper 17/17

Low, H., Meghir, C., and Pistaferri, L. (2010). Wage risk and employment risk over the life cycle. American Economic Review, 100(4):1432-1467

Low, H. and Pistaferri, L. (2015). Disability insurance and the dynamics of the incentive insurance trade-off. American Economic Review, 105(10):2986-3029

Meghir, C. and Pistaferri, L. (2011). Earnings, consumption and life cycle choices. In O. Ashenfelter and D. Card (editors), Handbook of Labor Economics, volume 4(b), 774-854. Elsevier

Nadaraya, E.A. (1964). On estimating regression. Theory of Probability 8 Its Applications, 9(1):141-142

Nelissen, J.H. (1998). Annual versus lifetime income redistribution by social security. Journal of Public Economics, 68(2):223-249

Nybom, M. (2017). The distribution of lifetime earnings returns to college. Journal of Labor Economics, 35(4):903-952

Panizza, U. (2002). Income inequality and economic growth: Evidence from American data. Journal of Economic Growth, 7(1):25-41

Pettersson, T. and Pettersson (2007). Lifetime redistribution through taxes, transfers and non-cash benefits. In Tomas, A. Harding, and A. Gupta (editors), Modelling our Future, chapter 8, 205-232. Elsevier

Piketty, T. and Saez, E. (2007). How progressive is the U.S. federal tax system? A historical and international perspective. Journal of Economic Perspectives, 21(1):3-24

Shaw, J. (2014 Aug). The redistribution and insurance value of welfare reform. Technical report, IFS Working Paper 14/21

Shorrocks, A.F. (2013). Decomposition procedures for distributional analysis: a unified framework based on the shapley value. Journal of Economic Inequality, 11(1):99-126

Socio-Economic Panel (2013). Data for years 1984-2012, version 29. SOEP

Storesletten, K., Telmer, C.I., and Yaron, A. (2004). Consumption and risk sharing over 
the life cycle. Journal of Monetary Economics., 51(3):609-633

Ter Rele, H. et al. (2007). Measuring the lifetime redistribution achieved by dutch taxation, cash transfer and non-cash benefits programs. Review of Income and Wealth, 53(2):335-362

Vickrey, W. (1939). Averaging of income for income-tax purposes. Journal of Political Economy, 47(3):379-397

Vickrey, W.S. (1947). Agenda for progressive taxation. The Ronald Press Company

Wagner, G., Frick, J., and Schupp, J. (2007). The German Socio-Economic Panel Study (SOEP) - Scope, evolution and enhancements. Schmollers Jahrbuch, 127(1):139-169

Wang, C., Caminada, K., and Goudswaard, K. (2012). The redistributive effect of social transfer programmes and taxes: A decomposition across countries. International Social Security Review, 65(3):27-48

Watson, G.S. (1964). Smooth regression analysis. Sankhyā: The Indian Journal of Statistics, Series A, 359-372 


\title{
Supplementary Web Appendix
}

\author{
(Intended for Online Publication)
}




\section{Appendix I: Pensions}

Individuals in old-age retirement (i.e., individuals who retired at age 60 or above in good health) receive pension benefits each year for the remainder of their lives. The annual pension benefit received by an individual who entered old-age retirement at age $R$ is given by:

$$
\text { Pension }_{i}=\alpha \times \bar{W}_{i, R} \times \text { PenPenalty }_{R} \times \operatorname{Exper}_{i, R}
$$

where $\alpha$ is a parameter that controls the generosity of pension benfits, $\bar{W}_{i, R}$ is the individual's annual pension-benefit-eligible labor earnings averaged over all years of employment prior to retirement, and PenPenalty ${ }_{R}$ is a penalty that reduces the individual's annual pension by $3.6 \%$ for each year that he retired before the age of 65 years (up to a maximum reduction of 18\%). Only annual labor earnings below approximately 58,000 euros are considered when calculating pension benefits. The taxation of pension benefits is described in Appendix II.

\section{Appendix II: Taxes}

Annual labor earnings above an exemption threshold of 8,584 euros are subject to a labor earnings tax. The labor earnings tax function is a smooth progressive function of taxable annual labor earnings with a marginal tax rate that ranges from $15 \%$ to $42 \%$. Annual interest income above an exemption threshold of 1,421 euros is taxed at a constant marginal rate of $25 \%$. Individuals pay a further tax (Solidaritaetszuschlag) of $5.5 \%$ of their tax liability on labor earnings and interest income. Individuals also pay a social security tax for health, unemployment and pension benefits. The social security tax is a flat rate tax of $21.5 \%(8.5 \%$ for health benefits, $3.25 \%$ for unemployment benefits, and $9.75 \%$ for pension benefits) on labor earnings below a cap of around 52,000 euros per year.

Fifty percent of annual pension benefit income in excess of an exemption threshold of 15,532 euros is taxed on the same basis as taxable labor earnings. We account for the taxation of pension benefits, along with all other taxes, when estimating the model and when using the estimated model to simulate datasets. However, because we focus on individuals younger than age 60 years, the taxation of pension benefits does not affect the decompositions presented in Sections 5 and 6 .

\section{Appendix III : Estimation sample}

The estimation sample is an unbalanced annual panel sample of men from years 2004-2012 of German Socio-Economic Panel. The estimation sample excludes individuals younger than 20 years or older than 65 years, individuals in education, East Germans, the self-employed and civil servants. Table SWA.1 provides definitions and descriptive statistics for the variables used in the analysis. 
Table SWA.1: Descriptive statistics

\begin{tabular}{ccccc}
\hline \hline Variable & Observations & Mean & Minimum & Maximum \\
\hline Age (years) & & & & \\
Employed & 15,862 & 45.08 & 20 & 64 \\
Nonemployed & 15,862 & 0.87 & 0 & 1 \\
Retired (disability-based or old-age) & 15,862 & 0.08 & 0 & 1 \\
Education (years) & 15,862 & 12.31 & 7 & 18 \\
Health & 15,862 & 0.83 & 0 & 1 \\
Experience (years) & 15,862 & 21.97 & 0 & 49 \\
Wage (euros per hour) & 13,812 & 16.75 & 4.96 & 39.19 \\
Wealth (euros) & 15,862 & 112,039 & 0 & 660,000 \\
& & & & \\
\hline \hline
\end{tabular}

Notes: Individuals working at least 20 hours per week are classified as employed. The small number of men observed in part-time employment are classified as nonemployed. The median hours of work per week for employees is 40. Years of education includes time spent in formal education and occupational training. Health is an indicator of good health, defined as neither being officially disabled nor assessing own health as "bad" or "very bad". Experience is defined as years spent in employment, where one year of pre-sample part-time employment is counted as half a year of experience. 'Wage' is the pre-tax hourly wage and is observed only for individuals in employment. Wealth is calculated by combining survey information about the net value of financial and real assets that was collected as part of the 2007 SOEP survey with information about financial and real savings that was collected in every year. 'Wealth' is left censored at zero and right censored at 660,000 euros. Wages and wealth are expressed in year 2005 prices.

\section{Appendix IV: Estimation}

In Appendix IV.1 we explain how we approximate the value function, in Appendix IV.2 we present the likelihood function, and in Appendix IV.3 we describe how we maximize the likelihood function.

\section{Appendix IV.1: Value function approximation}

We derive analytic expressions for the value function that appears in (8), starting from the following choice-specific value functions:

$$
V_{t}\left(c_{i, t}, l_{i, t}, \mathbf{s}_{i, t}\right)=\mathrm{U}\left(c_{i, t}, l_{i, t}, \epsilon_{i, t}\right)+\beta \mathrm{E}_{t}\left[V_{t+1}\left(\mathbf{s}_{i, t+1}\right) \mid \mathbf{s}_{i, t}, c_{i, t}, l_{i, t}\right] \quad \text { for } \quad t=20, \ldots, T
$$

where $\mathrm{E}_{T}\left[V_{T+1}\left(\mathbf{s}_{i, T+1}\right) \mid \mathbf{s}_{i, T}, c_{i, T}, l_{i, T}\right]=0$ (since period $T$ is the last period of the individual's life). Let $\mathbf{x}_{i, t}$ denote the age- $t$ state variables excluding the preference shocks. We decompose the choice-specific value functions into a systematic component and a random component, which corresponds to the preference shock:

$$
V_{t}\left(c_{i, t}, l_{i, t}, \mathbf{s}_{i, t}\right)=\bar{V}_{t}\left(c_{i, t}, l_{i, t}, \mathbf{x}_{i, t}\right)+\epsilon_{i, t}\left(c_{i, t}, l_{i, t}\right) \quad \text { for } \quad t=20, \ldots, T \text {. }
$$


Given the distributional assumptions about preference shocks (see Section 3.7), we have the following analytic expression for the expected age $t+1$ value function:

$$
\begin{aligned}
\mathrm{E}_{t}\left[V_{t+1}\left(\mathbf{s}_{i, t+1}\right) \mid \mathbf{s}_{i, t}, c_{i, t}, l_{i, t}\right]= & \sum_{\mathbf{x}_{t+1}} \log \left(\sum_{\{c, l\} \in \mathbb{D}\left(\mathbf{x}_{t+1}\right)} \exp \left(\bar{V}_{t+1}\left(c, l, \mathbf{x}_{i, t+1}\right)\right)\right) \times \\
& q\left(\mathbf{x}_{t+1} \mid \mathbf{x}_{t}, c_{i, t}, l_{i, t}\right) \text { for } t=20, \ldots, T-1,
\end{aligned}
$$

where $q\left(\mathbf{x}_{t+1} \mid \mathbf{x}_{t}, c_{i, t}, l_{i, t}\right)$ denotes the joint probability mass function of the state variables $\mathbf{x}_{i, t+1}$ conditional on the state variables $\mathbf{x}_{i, t}$ and conditional on the individual's consumption and labor supply outcome at age $t$ (since the choice set does not depend on preference shocks, $\left.\mathbb{D}\left(\mathbf{x}_{t}\right) \equiv \mathbb{D}\left(\mathbf{s}_{t}\right)\right)$.

We approximate the value function using recursive interpolation, working backwards from age $T$ (see Keane and Wolpin, 1994). In more detail, for each age, we evaluate the value function at set of grid points. The evaluation grid includes all possible values of health, labor supply outcome in the previous year, and unobserved productive type. The evaluation grid also includes 8 values of wealth $(0,10000,25000,50000,75000,100000,150000,700000)$, 6 values of experience $(0,10,20,30,40,50)$, and 4 values of education $(7,11,12,18)$ (giving a total of 2304 grid points). We then use a linear interpolation function to predict the value function at values of the state variables that are not included in the evaluation grid. The results are insensitive to increasing in the number grid points and changing the interpolation method.

\section{Appendix IV.2: Likelihood function}

The log likelihood function is given by:

$$
\mathcal{L}(\boldsymbol{\alpha}, \boldsymbol{\phi}, \boldsymbol{\psi})=\sum_{i=1}^{N} \log \left\{\sum_{j=1}^{3} \rho_{j} \prod_{t=\underline{t}_{i}}^{\bar{t}_{i}} P\left(l_{i, t} \mid \eta_{i}=\eta_{j}, \boldsymbol{\alpha}, \boldsymbol{\phi}, \boldsymbol{\psi}\right) f\left(\operatorname{Wage}_{i, t}^{*} \mid \eta_{i}=\eta_{j}, \boldsymbol{\psi}\right)\right\}
$$

where $N$ denotes the number of individuals in the sample, $\boldsymbol{\alpha}=\left\{\alpha_{1}, \alpha_{2}\right\}$ denotes the parameters of the utility function, $\phi=\left\{\phi_{1}^{s}, \ldots, \phi_{6}^{s}, \phi_{1}^{o}, \ldots, \phi_{6}^{o}\right\}$ denotes the parameters of the job separation and job offer probabilities, $\boldsymbol{\psi}=\left\{\psi_{1}, \ldots, \psi_{6}, \eta_{1}, \eta_{2}, \eta_{3}, \rho_{1}, \rho_{2}, \sigma_{\mu}^{2}\right\}$ denotes the parameters of the wage equation (including the wage measurement error variance), $\underline{t}_{i}$ and $\bar{t}_{i}$ denote individual $i$ 's age when we entered and when he left the sample, respectively, $P\left(l_{i, t} \mid \eta_{i}=\eta_{j}, \boldsymbol{\alpha}, \boldsymbol{\phi}, \boldsymbol{\psi}\right)$ denotes the probability of the individual's labor supply outcome at age $t$, conditional on being productive ability type $j$, and $f\left(\right.$ Wage $\left._{i, t}^{*} \mid \eta_{i}=\eta_{j}, \boldsymbol{\psi}\right)$ is the density of the sample wage observation, again conditional on the individual's productive ability type (recall, the sample log wage is equal to the actual log wage plus a normally distributed measurement error). To simplify notation, we set $f$ equal to one for nonemployed and retired individuals, for whom the wage is not observed.

Intuitively, each individual contributes to the likelihood the joint probability of his labor supply outcomes and sample wage values (when observed) over the years that he was in the sample. Conditional on an individual's productive ability type, labor supply outcomes and 
wages are independent over years. Given that the individual's productive ability type is unobserved to the econometrician, the individual's contribution to the sample likelihood is obtained by taking the product over the individual's conditional annual likelihood contributions and then integrating over the distribution of productive ability.

In the likelihood function, $P\left(l_{i, t} \mid \eta_{i}=\eta_{j}, \boldsymbol{\alpha}, \boldsymbol{\phi}, \boldsymbol{\psi}\right)$ denotes the probability of the individual's labor supply outcome at age $t$, conditional on his productive ability type. To calculate this probability, we start with joint probability of a consumption choice $m$, and the individual's labor supply outcome, conditional on the individual's productive ability type and his job offer and job separation status (which affects the choice set, $\mathbb{D}\left(\mathbf{x}_{i, t}\right)$ ):

$$
P\left(m, l_{i, t} \mid \eta_{i}=\eta_{j}, \mathrm{JO}_{i, t}, \mathrm{JS}_{i, t}, \boldsymbol{\alpha}, \boldsymbol{\phi}, \boldsymbol{\psi}\right)=\frac{\exp \left(\bar{V}_{t}\left(m, l_{i, t}, \mathbf{x}_{i, t}\right)\right)}{\sum_{\{c, l\} \in \mathbb{D}\left(\mathbf{x}_{i, t}\right)} \exp \left(\bar{V}_{t}\left(c, l, \mathbf{x}_{i, t}\right)\right)},
$$

where $\bar{V}_{t}()$ is the systematic component of the choice-specific value function given by (14). Summing over the possible consumption choices and integrating over the distributions of job offers and job separations gives the required probability:

$P\left(l_{i, t} \mid \eta_{i}=\eta_{j}, \boldsymbol{\alpha}, \boldsymbol{\phi}, \boldsymbol{\psi}\right)=\sum_{m} \iint P\left(m, l_{i, t} \mid \eta_{i}=\eta_{j}, \mathrm{JO}_{i, t}, \mathrm{JS}_{i, t}, \boldsymbol{\alpha}, \boldsymbol{\phi}, \boldsymbol{\psi}\right) d F\left(\mathrm{JO}_{i, t}\right) d F\left(\mathrm{JS}_{i, t}\right)$,

where $F\left(\mathrm{JO}_{i, t}\right)$ and $F\left(\mathrm{JS}_{i, t}\right)$ denote the cumulative distribution functions for job offers and job separations, respectively.

\section{Appendix IV.3: Maximization of the likelihood function}

We maximize the likelihood function using the two-stage procedure proposed by Arcidiacono and Jones (2003), which exploits the finite mixture structure of the unobserved productive ability in our model. We first apply a sequential and inefficient Expectation-Maximization (EM) algorithm. This provides good starting values for a subsequent full information maximum likelihood procedure (FIML) that utilizes the numerical gradient and the BHHH Hessian (Berndt et al., 1974). With the good starting values from the EM algorithm, the FIML procedure converges quickly. 


\section{Appendix V: Robustness checks}

Table SWA.2: Robustness of the results in Table 5 to measuring inequality using the squared coefficient of variation instead of the Theil index

\begin{tabular}{|c|c|c|c|c|}
\hline & \multicolumn{3}{|c|}{$\begin{array}{l}\text { Inequality of lifetime earnings and lifetime income } \\
(100 \times \text { squared coefficient of variation })\end{array}$} & \multirow{2}{*}{$\begin{array}{l}\text { Ratio of between- } \\
\text { endowment inequality } \\
\text { to total inequality }\end{array}$} \\
\hline & Total & Within-endowment & Between-endowment & \\
\hline $\begin{array}{l}\text { Earnings } \\
\text { (Labor earnings+ } \\
\text { interest income) }\end{array}$ & 8.68 & 1.28 & 7.40 & 0.84 \\
\hline $\begin{array}{l}\text { Income } \\
\text { (Earnings-taxes+transfers) }\end{array}$ & 4.12 & 0.53 & 3.59 & 0.85 \\
\hline $\begin{array}{l}\text { Share of earnings inequality offset } \\
\text { by the tax-and-transfer system }\end{array}$ & 0.53 & 0.59 & 0.51 & \\
\hline
\end{tabular}

Table SWA.3: Robustness of the results in Table 5 to measuring inequality using the mean logarithmic deviation instead of the Theil index

\begin{tabular}{|c|c|c|c|c|}
\hline & \multicolumn{3}{|c|}{$\begin{array}{l}\text { Inequality of lifetime earnings and lifetime income } \\
\qquad(100 \times \text { mean logarithmic deviation })\end{array}$} & \multirow{2}{*}{$\begin{array}{l}\text { Ratio of between- } \\
\text { endowment inequality } \\
\text { to total inequality }\end{array}$} \\
\hline & Total & Within-endowment & Between-endowment & \\
\hline $\begin{array}{l}\text { Earnings } \\
\quad \text { (Labor earnings+ } \\
\text { interest income) }\end{array}$ & 10.10 & 2.53 & 7.57 & 0.76 \\
\hline $\begin{array}{l}\text { Income } \\
\qquad \text { (Earnings-taxes+transfers) }\end{array}$ & 3.95 & 0.60 & 3.37 & 0.85 \\
\hline $\begin{array}{l}\text { Share of earnings inequality offset } \\
\text { by the tax-and-transfer system }\end{array}$ & 0.61 & 0.76 & 0.56 & \\
\hline
\end{tabular}


Table SWA.4: Robustness of the results in Table 5 to allowing four productive ability types

Inequality of lifetime earnings and lifetime income

$(100 \times$ Theil index $)$

Total Within-endowment Between-endowment

Ratio of betweenendowment inequality to total inequality

\section{Earnings \\ (Labor earnings+ \\ interest income)}

8.68

1.28

0.53

0.59
7.40
(Earnings-taxes+transfers)

Share of earnings inequality offset by the tax-and-transfer system

Notes: All calculations are based on a sample of 10,000 income trajectories of individuals aged 20-59 years inclusive simulated from an extended model that allows four productive ability types (instead of the three types that are allowed in the primary specification). The wage intercepts for the four productive ability types and the estimated fraction of each type (in parentheses) are: $2.212(0.176), 1.921(0.357), 1.638(0.317)$ and $1.287(0.150)$.

\section{Table SWA.5: Robustness of the results in Table 5 to allowing five productive ability types}

\begin{tabular}{|c|c|c|c|c|}
\hline & \multicolumn{3}{|c|}{$\begin{array}{l}\text { Inequality of lifetime earnings and lifetime income } \\
\qquad(100 \times \text { Theil index })\end{array}$} & \multirow{2}{*}{$\begin{array}{l}\text { Ratio of between- } \\
\text { endowment inequality } \\
\text { to total inequality }\end{array}$} \\
\hline & Total & Within-endowment & Between-endowment & \\
\hline $\begin{array}{l}\text { Earnings } \\
\text { (Labor earnings+ } \\
\text { interest income) }\end{array}$ & 8.29 & 1.03 & 7.26 & 0.88 \\
\hline $\begin{array}{l}\text { Income } \\
\qquad \text { (Earnings - taxes+transfers })\end{array}$ & 4.07 & 0.46 & 3.61 & 0.89 \\
\hline $\begin{array}{l}\text { Share of earnings inequality offset } \\
\text { by the tax-and-transfer system }\end{array}$ & 0.51 & 0.56 & 0.50 & \\
\hline
\end{tabular}

Notes: All calculations are based on a sample of 10,000 income trajectories of individuals aged 20-59 years inclusive simulated from an extended model that allows five productive ability types (instead of the three types that are allowed in the primary specification). The wage intercepts for the five productive ability types and the estimated fraction of each type (in parentheses) are: $2.282(0.137), 2.010(0.288), 1.772(0.298), 1.520$ (0.190) and $1.207(0.086)$. 
Table SWA.6: Robustness of the results in Table 6 to measuring inequality using the squared coefficient of variation instead of the Theil index

\begin{tabular}{lccc}
\hline \hline & & & \\
& Total & $\begin{array}{c}\text { Within-endowment } \\
\text { (Insurance) }\end{array}$ & $\begin{array}{c}\text { Between-endowment } \\
\text { (Redistribution) }\end{array}$ \\
\cline { 2 - 4 } Taxes & 0.26 & 0.09 & 0.29 \\
Unemployment insurance & 0.04 & 0.08 & 0.03 \\
Disability benefits & 0.01 & 0.10 & -0.01 \\
Social assistance & 0.16 & 0.22 & 0.14 \\
& & & \\
\hline \hline
\end{tabular}

Table SWA.7: Robustness of the results in Table 6 to measuring inequality using the mean logarithmic deviation instead of the Theil index

\begin{tabular}{lccc}
\hline \hline & & & \\
& Total & $\begin{array}{c}\text { Within-endowment } \\
\text { (Insurance) }\end{array}$ & $\begin{array}{c}\text { Between-endowment } \\
\text { (Redistribution) }\end{array}$ \\
\cline { 2 - 4 } Taxes & 0.22 & 0.08 & 0.26 \\
Unemployment insurance & 0.05 & 0.08 & 0.04 \\
Disability benefits & 0.00 & 0.03 & -0.01 \\
Social assistance & 0.34 & 0.58 & 0.26 \\
& & & \\
\hline \hline
\end{tabular}

Table SWA.8: Robustness of the results in Table 6 to allowing four productive ability types

\begin{tabular}{lccc}
\hline \hline & Total & $\begin{array}{c}\text { Within-endowment } \\
\text { (Insurance) }\end{array}$ & $\begin{array}{c}\text { Between-endowment } \\
\text { (Redistribution) }\end{array}$ \\
\cline { 2 - 4 } & & & \\
Taxes & 0.23 & 0.06 & 0.26 \\
Unemployment insurance & 0.04 & 0.08 & 0.03 \\
Disability benefits & 0.01 & 008 & -0.01 \\
Social assistance & 0.26 & 0.37 & 0.24 \\
& & & \\
\hline \hline
\end{tabular}

Notes: See notes to Table SWA.4.

Table SWA.9: Robustness of the results in Table 6 to allowing five productive ability types

\begin{tabular}{lccc}
\hline \hline & Total & $\begin{array}{c}\text { Within-endowment } \\
\text { (Insurance) }\end{array}$ & $\begin{array}{c}\text { Between-endowment } \\
\text { (Redistribution) }\end{array}$ \\
\cline { 2 - 4 } & & & \\
Taxes & 0.26 & 0.06 & 0.26 \\
Unemployment insurance & 0.03 & 0.08 & 0.03 \\
Disability benefits & 0.00 & 0.08 & -0.01 \\
Social assistance & 0.24 & 0.33 & 0.22 \\
& & & \\
\hline \hline
\end{tabular}

Notes: See notes to Table SWA.5. 
Table SWA.10: Robustness of the results in Table 8 to measuring inequality using the squared coefficient of variation instead of the Theil index

\begin{tabular}{|c|c|c|c|c|}
\hline & \multirow[b]{2}{*}{$\begin{array}{l}\text { Within-endowment } \\
\text { inequality in baseline }\end{array}$} & \multicolumn{3}{|c|}{$\Delta$ Within-endowment inequality } \\
\hline & & $\begin{array}{c}\text { Increased job } \\
\text { separation risk }\end{array}$ & $\begin{array}{l}\text { Decreased job } \\
\text { offer rate }\end{array}$ & $\begin{array}{l}\text { Increased risk of } \\
\text { bad health shocks }\end{array}$ \\
\hline $\begin{array}{l}\text { Lifetime earnings } \\
\text { (Labor earnings }+ \\
\text { interest income) }\end{array}$ & 1.03 & 0.11 & 0.45 & 0.19 \\
\hline $\begin{array}{l}\text { Lifetime income } \\
\quad \text { (Earnings-taxes+transfers) }\end{array}$ & 0.52 & 0.05 & 0.22 & 0.08 \\
\hline $\begin{array}{l}\text { Share of extra within- } \\
\text { endowment inequality offset } \\
\text { by the tax-and-transfer } \\
\text { system }\end{array}$ & & 0.54 & 0.52 & 0.59 \\
\hline
\end{tabular}

Table SWA.11: Robustness of the results in Table 8 to measuring inequality using the mean logarithmic deviation instead of the Theil index

\begin{tabular}{|c|c|c|c|c|}
\hline & \multirow[b]{2}{*}{$\begin{array}{l}\text { Within-endowment } \\
\text { inequality in baseline }\end{array}$} & \multicolumn{3}{|c|}{$\Delta$ Within-endowment inequality } \\
\hline & & $\begin{array}{c}\text { Increased job } \\
\text { separation risk }\end{array}$ & $\begin{array}{c}\text { Decreased job } \\
\text { offer rate }\end{array}$ & $\begin{array}{l}\text { Increased risk of } \\
\text { bad health shocks }\end{array}$ \\
\hline $\begin{array}{l}\text { Lifetime earnings } \\
\text { (Labor earnings+ } \\
\text { interest income) }\end{array}$ & 2.53 & 0.21 & 1.27 & 0.38 \\
\hline $\begin{array}{l}\text { Lifetime income } \\
\quad \text { (Earnings-taxes+transfers) }\end{array}$ & 0.60 & 0.05 & 0.24 & 0.09 \\
\hline $\begin{array}{l}\text { Share of extra within- } \\
\text { endowment inequality offset } \\
\text { by the tax-and-transfer } \\
\text { system }\end{array}$ & & 0.77 & 0.81 & 0.77 \\
\hline
\end{tabular}


Table SWA.12: Robustness of the results in Table 8 to allowing four productive ability types

\begin{tabular}{|c|c|c|c|c|}
\hline & \multirow[b]{2}{*}{$\begin{array}{l}\text { Within-endowment } \\
\text { inequality in baseline }\end{array}$} & \multicolumn{3}{|c|}{$\Delta$ Within-endowment inequality } \\
\hline & & $\begin{array}{l}\text { Increased job } \\
\text { separation risk }\end{array}$ & $\begin{array}{l}\text { Decreased job } \\
\text { offer rate }\end{array}$ & $\begin{array}{l}\text { Increased risk of } \\
\text { bad health shocks }\end{array}$ \\
\hline $\begin{array}{l}\text { Lifetime earnings } \\
\text { (Labor earnings+ } \\
\text { interest income) }\end{array}$ & 1.28 & 0.10 & 0.38 & 0.19 \\
\hline $\begin{array}{l}\text { Lifetime income } \\
\quad \text { (Earnings-taxes+transfers) }\end{array}$ & 0.53 & 0.05 & 0.16 & 0.07 \\
\hline $\begin{array}{l}\text { Share of extra within- } \\
\text { endowment inequality offset } \\
\text { by the tax-and-transfer } \\
\text { system }\end{array}$ & & 0.50 & 0.57 & 0.62 \\
\hline
\end{tabular}

Notes: See notes to Table SWA.4.

Table SWA.13: Robustness of the results in Table 8 to allowing five productive ability types

\begin{tabular}{|c|c|c|c|c|}
\hline & \multirow[b]{2}{*}{$\begin{array}{l}\text { Within-endowment } \\
\text { inequality in baseline }\end{array}$} & \multicolumn{3}{|c|}{$\Delta$ Within-endowment inequality } \\
\hline & & $\begin{array}{l}\text { Increased job } \\
\text { separation risk }\end{array}$ & $\begin{array}{l}\text { Decreased job } \\
\text { offer rate }\end{array}$ & $\begin{array}{l}\text { Increased risk of } \\
\text { bad health shocks }\end{array}$ \\
\hline $\begin{array}{l}\text { Lifetime earnings } \\
\text { (Labor earnings+ } \\
\text { interest income) }\end{array}$ & 1.03 & 0.09 & 0.38 & 0.17 \\
\hline $\begin{array}{l}\text { Lifetime income } \\
\qquad(\text { Earnings - taxes +transfers })\end{array}$ & 0.46 & 0.05 & 0.18 & 0.07 \\
\hline $\begin{array}{l}\text { Share of extra within- } \\
\text { endowment inequality offset } \\
\text { by the tax-and-transfer } \\
\text { system }\end{array}$ & & 0.51 & 0.54 & 0.57 \\
\hline
\end{tabular}

Notes: See notes to Table SWA.5.

Table SWA.14: Robustness of the results in Table 9 to measuring inequality using the squared coefficient of variation instead of the Theil index

\begin{tabular}{lccc}
\hline \hline & $\begin{array}{c}\text { Increased job } \\
\text { separation risk }\end{array}$ & $\begin{array}{c}\text { Decreased job } \\
\text { offer rate }\end{array}$ & $\begin{array}{c}\text { Increased risk of } \\
\text { bad health shocks }\end{array}$ \\
\cline { 2 - 4 } Taxes & 0.11 & 0.10 & 0.10 \\
Unemployment insurance & 0.09 & 0.03 & 0.05 \\
Disability benefits & 0.10 & 0.05 & 0.19 \\
Social assistance & 0.24 & 0.34 & 0.25 \\
& & & \\
\hline \hline
\end{tabular}


Table SWA.15: Robustness of the results in Table 9 to measuring inequality using the mean logarithmic deviation instead of the Theil index

\begin{tabular}{lccc}
\hline \hline & $\begin{array}{c}\text { Increased job } \\
\text { separation risk }\end{array}$ & $\begin{array}{c}\text { Decreased job } \\
\text { offer rate }\end{array}$ & $\begin{array}{c}\text { Increased risk of } \\
\text { bad health shocks }\end{array}$ \\
\cline { 2 - 4 } Taxes & 0.08 & 0.08 & 0.08 \\
Unemployment insurance & 0.08 & 0.02 & 0.05 \\
Disability benefits & 0.03 & 0.01 & 0.07 \\
Social assistance & 0.57 & 0.70 & 0.58 \\
& & & \\
\hline \hline
\end{tabular}

Table SWA.16: Robustness of the results in Table 9 to allowing four productive ability types

\begin{tabular}{lccc}
\hline \hline & $\begin{array}{c}\text { Increased job } \\
\text { separation risk }\end{array}$ & $\begin{array}{c}\text { Decreased job } \\
\text { offer rate }\end{array}$ & $\begin{array}{c}\text { Increased risk of } \\
\text { bad health shocks }\end{array}$ \\
\cline { 2 - 4 } Taxes & 0.11 & 0.08 & 0.08 \\
Unemployment insurance & 0.09 & 0.02 & 0.03 \\
Disability benefits & 0.08 & 0.03 & 0.16 \\
Social assistance & 0.23 & 0.44 & 0.35 \\
\hline \hline
\end{tabular}

Notes: See notes to Table SWA.4.

Table SWA.17: Robustness of the results in Table 9 to allowing five productive ability types

\begin{tabular}{lccc} 
& $\begin{array}{c}\text { Increased job } \\
\text { separation risk }\end{array}$ & $\begin{array}{c}\text { Decreased job } \\
\text { offer rate }\end{array}$ & $\begin{array}{c}\text { Increased risk of } \\
\text { bad health shocks }\end{array}$ \\
\cline { 2 - 4 } Taxes & 0.09 & 0.09 & 0.08 \\
Unemployment insurance & 0.10 & 0.02 & 0.04 \\
Disability benefits & 0.08 & 0.05 & 0.15 \\
Social assistance & 0.24 & 0.38 & 0.30
\end{tabular}

Notes: See notes to Table SWA.5. 